\title{
Physical and chemical characterisation of PM emissions from two ships operating in European Emission Control Areas
}

\author{
J. Moldanová ${ }^{1}$, E. Fridell ${ }^{1}$, H. Winnes ${ }^{1}$, S. Holmin-Fridell ${ }^{1,2, *}$, J. Boman ${ }^{2}$, A. Jedynska ${ }^{3}$, V. Tishkova ${ }^{4}$, B. Demirdjian ${ }^{5}$, \\ S. Joulie ${ }^{4}$, H. Bladt ${ }^{6}$, N. P. Ivleva ${ }^{6}$, and R. Niessner ${ }^{6}$ \\ ${ }^{1}$ IVL, Swedish Environmental Research Institute, P.O. Box 53021, 40014 Gothenburg, Sweden \\ ${ }^{2}$ Department of Chemistry and Molecular Biology, Atmospheric Science, University of Gothenburg, 412 96, \\ Gothenburg, Sweden \\ ${ }^{3}$ TNO, Applied Environmental Chemistry, P.O. Box 80015, 3508 TA Utrecht, the Netherlands \\ ${ }^{4}$ CEMES/CNRS, 29 rue Jeanne Marvig BP 94347, 31055, Toulouse Cedex 4, France \\ ${ }^{5}$ Aix-Marseille Univ., CNRS, CINaM UMR7325, 13288, Marseille, France \\ ${ }^{6}$ Chair for Analytical Chemistry, Institute of Hydrochemistry, Technische Universität München, 81377 Munich, Germany \\ *currently at: SMHI, 60176, Norrköping, Sweden
}

Correspondence to: J. Moldanová (janam@ivl.se)

Received: 4 April 2013 - Published in Atmos. Meas. Tech. Discuss.: 22 April 2013

Revised: 23 October 2013 - Accepted: 6 November 2013 - Published: 17 December 2013

\begin{abstract}
In this paper emission factors (EFs) for particulate matter (PM) and some sub-components as well as gaseous substances were investigated in two onboard measurement campaigns. Emissions from two 4-stroke main engines were measured under stable-load conditions. The impact of varying engine load on the emissions was investigated on one of the engines, and the impact of fuel quality on the other, where heavy fuel oil (HFO) with sulphur content $1 \%$ and $0.5 \%$ and marine gas oil (MGO) with sulphur content $0.1 \%$ were used. Furthermore, emissions from one auxiliary engine were studied. The measured EFs for PM mass were in the range of 0.3 to $2.7 \mathrm{~g} \mathrm{~kg}^{-1}$ fuel with the lowest values for emissions from the combustion of MGO, and the highest values for HFO with a sulphur content of $1 \%$. The PM mass size distribution was dominated by particles in accumulation mode. Emission factors for particle numbers $\mathrm{EF}(\mathrm{PN})$ in the range of $5 \times 10^{15}-1 \times 10^{17} \# \mathrm{~kg}^{-1}$ fuel were found, the number concentration was dominated by particles in the ultrafine mode and ca. 2/3 of the particle number were non-volatile.

The most abundant component of the PM mass was organic carbon, making up 25-60\% of the PM. The measured EFs for organic carbon (OC) were $0.6 \mathrm{~g} \mathrm{~kg}^{-1}$ fuel for HFO and $0.2 \mathrm{~g} \mathrm{~kg}^{-1}$ fuel for MGO. Elemental carbon (EC) made up $10-38 \%$ of the PM mass, with no significant differences between HFO and MGO fuels. The concentrations of metals
\end{abstract}

on sampled filters were investigated with energy dispersive $\mathrm{X}$-ray fluorescence (EDXRF) and the detected metal elements in exhaust when using HFO was concluded to originate from both the fuel $(\mathrm{V}, \mathrm{Ni}, \mathrm{Fe})$ and the lubricant $(\mathrm{Ca}$, $\mathrm{Zn}$ ), while for the case of MGO combustion, most of the metals were concluded to originate from the lubricants. The measured emission factors for sulphate particles, $\mathrm{EF}\left(\mathrm{SO}_{4}^{2-}\right)$, were low, ca. $0.1-0.2 \mathrm{~g} \mathrm{~kg}^{-1}$ fuel for HFO with $1 \%$ sulphur, $0.07-0.09 \mathrm{~g} \mathrm{~kg}^{-1}$ fuel for HFO with $0.5 \%$ sulphur and $0.003-0.006 \mathrm{~g} \mathrm{~kg}^{-1}$ fuel for MGO. This corresponds to $0.1-$ $0.8 \%$ and $0.1-0.6 \%$ of fuel S converted to PM sulphate for HFO and MGO, respectively.

Scanning transmission electron microscopy (STEM) images of the collected PM showed three different types of particles: relatively pure soot; char and char-mineral particles; and amorphous, probably organic particles containing inorganic impurities. The maps of elements obtained from STEM showed a heterogeneous composition of primary soot particles with respect to the trace metals and sulphur. Temperature-programmed oxidation (TPO) of PM showed higher soot oxidation reactivity compared to automotive diesel soot, PM from the HFO exhaust being more reactive than PM from the MGO exhaust. Oxidative potential measured as the rate of consumption of Dithiothreitol (DTT) was for the first time measured on PM from 
ship exhaust. The obtained values were between 0.01 and $0.04 \mathrm{nmol}$ DTT $\mathrm{min}^{-1} \mu \mathrm{g}^{-1} \mathrm{PM}$, which is quite similar to oxidative potentials of PM collected at urban and traffic sites.

The data obtained during the experiments add information about emission factors for both gaseous and PM-bound compounds from ship engines using different fuels and under different engine-load conditions. Observed variability of the EFs illustrates uncertainties of these emission factors as a result of influences from fuel and lubricant composition, from differences between individual engines and from the differences in sampling conditions.

\section{Introduction}

Emissions of particulate matter (PM) from shipping contribute significantly to the anthropogenic burden of PM on global, regional and urban scales, the last two mainly in coastal and harbour regions. The recent emission inventories indicate that on the European scale, international shipping in seas surrounding Europe emits over $20 \%$ of the EU-27 anthropogenic PM emission totals (www.emep.int). In many harbour cities the PM emissions from shipping make significant contribution to land-based sources (e.g. Snijder et al., 2008; Haeger-Eugensson et al., 2010; Hong Kong EPD, 2012). In addition to the primary emitted PM, the gaseous emissions contribute to air pollution with secondary PM formed after being processed in the atmosphere. The environmental effects of PM from shipping include negative impact on human health through increased concentrations of particles in many coastal areas and harbour cities and the climate impact (Eyring et al., 2010, and references therein).

The increase of both relative and absolute contributions of emissions from shipping to the anthropogenic emission burden and its negative environmental impacts have been recognised for some time (Endresen et al., 2003; Eyring et al., 2005; Corbett et al., 2007). The main gaseous species emitted by shipping are $\mathrm{CO}_{2}, \mathrm{NO}_{\mathrm{x}}$ and $\mathrm{SO}_{2}(\mathrm{CO}$ and volatile organic compounds, VOCs, are of minor importance). The reason for the high contribution of navigation to the emission totals is the fact that shipping emissions have been, in contrast to the land sources, unregulated for a long time; only in last few years has regulation gradually been entering into force through Annex VI of the MARPOL convention of International Maritime Organisation (IMO). Annex VI, which came into force in May 2005 (IMO, 2008), targets emissions of sulphur through maximum allowed fuel sulphur content (FSC) and to some extent emissions of $\mathrm{NO}_{\mathrm{x}}$. Emissions of PM are addressed indirectly through decrease of formation of secondary PM from the reductions in $\mathrm{SO}_{2}$ and $\mathrm{NO}_{\mathrm{x}}$. Regulations introduced by Annex VI will also impact emissions of the primary PM due to enforced improvements in fuel quality associated with reduction of the fuel sulphur content and the effect of engine improvements as well as installations of emission cleaning technologies. These effects are, however, very uncertain, as only few measurements of PM mass and PM composition providing this information are available. The Marine Environmental Protection Committee (MEPC) of IMO has recently been discussing the impact of black carbon (BC) on the Arctic, potentially considering future regulation in the region. While development of distinct exhaust aftertreatment systems for the reduction of PM emissions is well-progressed in automotive industry, maritime applications are rare. In order to set and subsequently meet limitations on particulate exhaust, an extensive characterisation of such emission is essential.

The PM emitted by ship engines consists of organic carbon (OC), elemental or black carbon (EC/BC), sulphate, inorganic compounds containing $\mathrm{V}, \mathrm{Ni}, \mathrm{Ca}, \mathrm{Zn}$ and other metals and sulphate-associated water (Agrawal et al., 2008; Petzold et al., 2008; Moldanová et al., 2009). The chemical composition and physical properties of PM vary with type of fuel burned, type of engine and engine operation mode. While primary $\mathrm{PM}$ emissions of species like $\mathrm{V}, \mathrm{Ni}$ and $\mathrm{Ca}$ are supposed to be determined by the composition of fuel and lubricant oil, it has been shown that emissions of particulate OC, $\mathrm{EC}$ and sulphate are affected both by fuel quality and by operation mode of the engine (Petzold et al., 2010; Ristimaki et al., 2010).

Chemical and microphysical properties also have implications for the climate impact of shipping. BC is an important climate-warming compound with both direct and indirect climate effects, the later through decreasing the albedo of bright surfaces in polar regions. The BC emission factors for shipping have recently been reviewed by Lack and Corbett (2012) who found rather complex relations between $\mathrm{BC}$ emissions from heavy fuel oil (HFO) and marine distilled fuels, showing often, but not always, a decrease of $\mathrm{BC}$ emissions with improved fuel quality from HFO to distilled fuel. The chemical composition of PM affects also hygroscopic properties of the emitted particles and with that their ability to form cloud condensation nuclei (CCN) and modify clouds (Lauer et al., 2007).

In this study composition of PM and emission factors (EF) of different PM compounds from several in-operation ship engines burning different marine fuels have been investigated. The chemical characterisation of PM was complemented with transmission electron microscopy (TEM) and scanning transmission electron microscopy (STEM) analyses and with investigation of the toxic properties of the PM. Furthermore, temperature-programmed oxidation (TPO) analysis was used to investigate oxidation reactivity of exhaust particles, information especially needed for design of particulate mass reducing units. 


\section{Methods}

\subsection{The measurement campaigns}

Two measurement campaigns were performed; the first was performed on a RoRo/cassette carrier ship $(\mathrm{RoRo}=$ roll on, roll off; the cargo is driven in) in October 2010. The ship was travelling in the Baltic Sea. The measurements were performed on a 4-stroke diesel main engine (ME) Wärtsilä Vasa $12 \mathrm{~V} 32 \mathrm{D}$ with a maximum rated power (MRP) of $4440 \mathrm{~kW}$ and a nominal engine speed of $750 \mathrm{rpm}$ and on a Wärtsilä auxiliary engine (AE) with a MRP of $870 \mathrm{~kW}$. The exhaust compounds were probed for the ME at engine loads of 80 and $30 \%$ of MRP, and for the AE at $47 \%$ of MRP. The engine load and fuel consumption were measured manually with the help of the fuel rack and a fuel flowmeter. Both parameters were stable during the measurements. Data on technical parameters and engine operation conditions are presented in Tables S1 and S2 in the Supplement. During the campaign the main engine burned heavy fuel oil (HFO) with $\sim 1 \mathrm{wt} \%$ fuel sulphur content (FSC) and the auxiliary engine marine gas oil (MGO) with FSC of $\sim 0.1 \mathrm{wt} \%$. Fuel and lubricant from ME and fuel from $\mathrm{AE}$ were analysed for elemental composition, density and other parameters by DNV Petroleum Services. Results of these analyses are summarised in Table S3 in the Supplement. Throughout this report, the different measurements will be abbreviated as S1_HFO1\%_ME-full (ME at engine load $80 \%$ ), S1_HFO1\%_ME-low (ME at engine load $30 \%$ ) and S1_MGO_AE (AE at engine load $47 \%$ ).

The second measurement campaign was performed on a cargo/passenger ferry on a regular traffic service between Sweden and Germany in March-April 2010. Basic information about the ship is provided in Table $\mathrm{S} 1$ in the Supplement. The ship machinery comprised four 4-stroke diesel engines, Sulzer 8ZAL40S, with a MRP of $6000 \mathrm{~kW}$ each and a nominal engine speed of $510 \mathrm{rpm}$. All measurements were performed on one of the engines. The measurements were completed on an engine operating on $57 \%$ engine load. The engine load was monitored continuously through the scavenge air pressure. The fuel consumption was calculated from the engine trial report data provided by the engine producer. During the campaign three different fuels were tested: HFO with $\mathrm{S}$ content $1 \mathrm{wt} \%$, HFO with $\mathrm{S}$ content $0.5 \mathrm{wt} \%$ and MGO (FSC $\sim 0.1 \mathrm{wt} \%$ ). For further engine and fuel details, see Tables S2 and S3, respectively. The different measurements from this vessel will be abbreviated as S2_HFO1\%_MEfull (ME at engine load 57\%), S2_HFO0.5\%_ME-full and S2_MGO_ME-full. In the text a measurement on 1 engine with 1 constant engine load and 1 fuel type is called an experiment.

\subsection{Sampling conditions and online measurements}

The measurements were carried out on exhaust that was extracted from the exhaust channel with an isokinetic probe. The probe was connected to a Dekati Fine Particle Sampler (FPS-4000) system. In the FPS system, the warm exhaust was first diluted with heated cleaned air (primary dilution) and thereafter with non-heated cleaned air (ejector dilution). The temperature of the sampled gas was monitored after the heated dilution (temperature T1) and in the outlet of the FPS (T2). For sampling of PM mass and composition, $\mathrm{PM}_{2.5}$ and $\mathrm{PM}_{10}$ cyclones (Apex Instruments) followed by filter holders, vacuum pumps and gas meters were connected to the FPS system (Fig. S1). Dilution ratios were monitored by FPS and by parallel measurement of $\mathrm{NO}_{\mathrm{x}}$ in the exhaust channel and after the FPS instrument. Dilution ratios during the filter sampling were 15-20. The dilution ratios and temperatures $\mathrm{T} 1$ and $\mathrm{T} 2$ for all experiments are presented in Table 1 . In ambient conditions the initial plume dilution rate corresponding to a plume age of $\sim 1 \mathrm{~s}$ is typically $10-40$ (von Glasow et al., 2003; Chosson et al., 2008). During this initial dilution, the plume temperature drops to a temperature close to the ambient one. The dilution rates and temperatures reached after the primary dilution during our sampling are thus realistic for the ambient conditions.

For measurements of particle number concentrations (PN) and particle size distributions, online instruments were used. Particles in a size range of 5.6-560 nm were monitored with an EEPS (Engine Exhaust Particle Sizer, Model 3090, TSI Inc.). The EEPS measures particles divided into 32 electric mobility diameters. A resolution of $1 \mathrm{~s}$ was used. Particles in the size range $>300 \mathrm{~nm}$ were measured with an aerosol spectrometer GRIMM 1-108 that detects particles with optical diameter in the size range $300 \mathrm{~nm}-20 \mu \mathrm{m}$, divided into 15 size channels with a $1 \mathrm{~s}$ time resolution. The two aerosol instruments were coupled in parallel after the secondary dilution (Dekati Axial Diluter, DAD-100); optionally, a Dekati Thermodenuder ELA 423 (TD) was connected before the aerosol instruments to measure the ratio of volatile to nonvolatile particles. Size-dependent particle losses in the thermodenuder (up to $30 \%$ ) can be calculated by an empirical function given by the instrument producer. This function was verified under our experimental conditions through comparison of particle size-resolved concentrations bypassing and passing the cold thermodenuder with the calculated losses. All volatility data presented here are corrected for the particle losses in the thermodenuder.

Concentrations of a number of gas constitutes were measured continuously in the hot exhaust. Nitrogen oxides (Horiba PG-250 chemiluminescence instrument), carbon monoxide and carbon dioxide (Horiba PG-250 NDIR), oxygen (Horiba PG-250 galvanic cell), total hydrocarbons (Bernath Atomic BA 3006 FID), and sulphur dioxide (Horiba PG-250 NDIR) were monitored. 
Table 1. Matrix of analyses performed on filter samples from ship campaigns S1 and S2. DR - dilution ratio used during the sampling, T1 and T2 - sample temperatures after primary and secondary dilution in the FPS instrument. Filter material: PTFE - PTFE membrane filters, Quartz - quartz fibre filters, CF\&Ge - holders with $\mathrm{Cu}$ microgrids with amorphous carbon holey film and Ge windows. Analyses: grav. gravimetry, BC - analysis for BC with transmissometer, IC - ion chromatography, XRF - EDXRF, EC/OC - Thermal optical analysis for EC and OC, ox. pot. - oxidative potential tested with DTT assay, microscopy - transmission electron microscopy, FTIR and Raman.

\begin{tabular}{|c|c|c|c|c|c|c|}
\hline Experiment & DR & $\mathrm{T} 1\left[{ }^{\circ} \mathrm{C}\right]$ & $\mathrm{T} 2\left[{ }^{\circ} \mathrm{C}\right]$ & Filter & Analyses & PM metrics \\
\hline S1_HFO1\%_ME-full & 28.3 & 136.2 & 40.1 & PTFE & grav., BC, XRF, IC & TSP, $\mathrm{PM}_{10}, \mathrm{PM}_{1}$ \\
\hline S1_HFO1\%_ME-full & 28.3 & 136.2 & 40.1 & PTFE & XRF & $\mathrm{PM}_{10}, \mathrm{PM}_{1}$ \\
\hline S1_HFO1\%_ME-full & 28.3 & 136.2 & 40.1 & Quartz & EC/OC, ox. pot. & $\mathrm{TSP}, \mathrm{PM}_{10}, \mathrm{PM}_{1}$ \\
\hline S1_HFO1\%_ME-full & 28.3 & 136.2 & 40.1 & PTFE & ox. pot. & TSP, $\mathrm{PM}_{1}$ \\
\hline S1_HFO1\%_ME-full & 28.3 & 136.2 & 40.1 & $\mathrm{CF} \& \mathrm{Ge}$ & microscopy & TSP \\
\hline S1_HFO1\%_ME-low & 26.0 & 89.7 & 35.1 & PTFE & grav., BC, XRF, IC & TSP, $\mathrm{PM}_{10}, \mathrm{PM}_{1}$ \\
\hline S1_HFO1\%_ME-low & 26.0 & 89.7 & 35.1 & Quartz & $\mathrm{EC} / \mathrm{OC}$ & TSP, $\mathrm{PM}_{1}$ \\
\hline S1_MGO_AE & 31.5 & 105.0 & 29.2 & PTFE & grav., BC, XRF, IC & TSP, $\mathrm{PM}_{10}, \mathrm{PM}_{1}$ \\
\hline S1_MGO_AE & 31.5 & 105.0 & 29.2 & PTFE & $\mathrm{XRF}$ & $\mathrm{PM}_{1}$ \\
\hline S1_MGO_AE & 31.5 & 105.0 & 29.2 & Quartz & $\mathrm{EC} / \mathrm{OC}, \mathrm{c}$ & TSP, $\mathrm{PM}_{10}, \mathrm{PM}_{1}$ \\
\hline S1_MGO_AE & 31.5 & 105.0 & 29.2 & PTFE & ox. pot. & TSP, $\mathrm{PM}_{1}$ \\
\hline S1_MGO_AE & 31.5 & 105.0 & 29.2 & $\mathrm{CF} \& \mathrm{Ge}$ & microscopy & TSP \\
\hline S2_HFO1\%_ME-full & 17.9 & 106.8 & 39.1 & PTFE & grav., BC, XRF & $\mathrm{PM}_{10}, \mathrm{PM}_{2.5}$ \\
\hline S2_HFO1\%_ME-full & 17.9 & 106.8 & 39.1 & PTFE & ox. pot. & $\mathrm{PM}_{2.5}$ \\
\hline S2_HFO0.5\%_ME-full* & $23.5 / 27.7$ & $132.9 / 149.0$ & $39.0 / 50.1$ & PTFE & grav., $\mathrm{BC}, \mathrm{XRF}$ & $\mathrm{PM}_{10}, \mathrm{PM}_{2.5}$ \\
\hline S2_HFO0.5\%_ME-full* & $23.5 / 27.7$ & $132.9 / 149.0$ & $39.0 / 50.1$ & Quartz & $\mathrm{EC} / \mathrm{OC}$ & $\mathrm{PM}_{10}, \mathrm{PM}_{2.5}$ \\
\hline S2_HFO0.5\%_ME-full* & $23.5 / 27.7$ & $132.9 / 149.0$ & $39.0 / 50.1$ & PTFE & ox. pot. & $\mathrm{PM}_{2.5}$ \\
\hline S2_MGO_ME-full & 28.8 & 141.4 & 41.9 & PTFE & grav., BC, XRF & $\mathrm{PM}_{10}, \mathrm{PM}_{2.5}$ \\
\hline S2_MGO_ME-full & 28.8 & 141.4 & 41.9 & PTFE & ox. pot. & $\mathrm{PM}_{2.5}$ \\
\hline
\end{tabular}

* Sampling in 2 periods with different sampling conditions.

The temperature and humidity of the engine inlet air were monitored. The exhaust gas flow was measured with a pitot tube during each sampling experiment. The exhaust temperature was measured several times during each sampling period. Further details on the gas measurement methodologies can be found in Cooper $(2001,2003)$.

\subsection{PM filter analyses}

Several sets of filter samples were collected during the campaigns. Table 1 summaries filter samples and analyses performed at different laboratories. The goal of the sampling was to obtain the emission factors for the following PM parameters: $\mathrm{PM}$ mass, elemental carbon (EC), black carbon $(\mathrm{BC})$, organic carbon (OC), elemental composition and ionic composition. These emission factors further distinguish between emission factors (EFs) for total suspended particulate matter (TSP), $\mathrm{PM}_{10}$ and $\mathrm{PM}_{2.5}$ or $\mathrm{PM}_{1}$. Additional analyses for oxidative potential, microphysical and chemical characterisation and for oxidation reactivity by TPO were performed.

Some analyses were done by several techniques or at several laboratories to address uncertainties of the analyses. $\mathrm{BC} / \mathrm{EC}$ was analysed as EC with Sunset technique and also as BC by 2 optical methods using transmissometer and reflectometer. In this way, some uncertainties of both methods were addressed. Elemental composition was analysed by energy dispersive X-ray fluorescence (EDXRF) and supported by ion chromatography.

For all analyses, multiple samples were taken for at least one experiment and one PM metrics. The sampling matrix is not full for all analyses due to the time and budget constraints of the measurement campaigns. More details of individual analyses are given later in this section.

For gravimetric analyses, a Mettler Toledo model MT5 balance was used. The balance was calibrated to an uncertainty limit of $\pm 3 \mu \mathrm{g}$ in the range $0-10000 \mu \mathrm{g}$ and $\pm 7 \mu \mathrm{g}$ in the range $10000-100000 \mu \mathrm{g}$. The gravimetric analyses were performed with polytetrafluoroethylene (PTFE) Mitex membrane filters.

The analysis of EC/OC is based on the thermal optical method as described in the American standard method, NIOSH 5040 (NIOSH, 2003). The EUSAAR (European Supersites for Atmospheric Aerosol Research) 2 protocol (Cavalli et al., 2010) was used for the temperature settings. A $1 \mathrm{~cm}^{2}$ piece of the sample taken on quartz fibre filters was used for the measurement. $\mathrm{OC}$ is removed from the filter in the temperature range of $200-650^{\circ} \mathrm{C}$ in a non-oxidising carrier gas (helium). EC is then removed in the temperature range of $500-850^{\circ} \mathrm{C}$ in a mixture of helium and oxygen. The originated $\mathrm{CO}_{2}$ is then converted to methane and detected by flame ionisation detection (FID). Quantification takes place based on a gas mixture of $5 \%$ methane in helium. 
Sucrose is used as a control standard. Correction for pyrolysis is carried out by measurement of light transmission. The total uncertainty of the method amounts $31 \%$. The optical method used for correction for pyrolysis was shown to impact the obtained EC; Chow et al. (2004) published results where the ratio of reflectance- to transmission-corrected EC for EUSAAR 2 protocol was about 1.7. Maenhaut (2009) discussed that there is a tendency for larger EC/TC ratios with reflectance correction method compared to the transmission method when using the same thermal protocol.

For analyses of black carbon (BC), a SootScan Transmissometer Model OT21 (Magee Scientific, Berkeley, USA) was used. Attenuation of light of two wavelengths, 880 and $370 \mathrm{~nm}$, passing the examined filter sample is measured and compared with attenuation by a blank filter. The detected attenuation of IR-light $(880 \mathrm{~nm})$ comes from absorption and scattering of $\mathrm{PM}$ and is proportional to the surface density of $\mathrm{BC}$ mass on the filter with mass-specific absorption coefficient (MAC). MAC is dependent on the filter material, the measurement method for the $\mathrm{BC} / \mathrm{EC}$ mass used for calibration and also the type of the PM analysed. In this study MAC $=12.6$ has been used. This MAC is the Improve EC calibration based on EC measured by thermal optical method with light reflection correction for pyrolysis (Hansen, 2005). This MAC corresponds best to the range of absorption coefficients found by Frank et al. (2010) in a comparison of IR light attenuation measured on PTFE filter samples and EPA's EC measured with NIOSH-type thermal optical method with light transmission correction, which was $10-12 \mathrm{~m}^{2} \mathrm{~g}^{-1}$ for the non-woodsmoke PM. Attenuation in wavelength $370 \mathrm{~nm}$ has not been evaluated, as the OC obtained from this measurement is only indicative.

$\mathrm{BC}$ has also been analysed with a Smoke Stain EEL M43D reflectometer. In the reflectometer a white-light source is placed on top of the filter. The light passes through the filter and thereafter reflects back through the filter to a detector. During the double pass through the filter, light is absorbed by all black constituents on the filter. The amount of light that is detected after the double pass through the filter is compared with a blank filter of the same type which is set to $100 \%$ reflection. The absorbed light can be converted to $\mathrm{BC}$ given in $\mu \mathrm{g} \mathrm{m}^{-3}$ (Quincey, 2007; Butterfield et al., 2010). A detection limit of $13 \mathrm{ng} \mathrm{cm}^{-2}$ of the filter area was determined by analysis of blank polycarbonate membrane filters at University of Gothenburg (Pettersson et al., 2011).

The PM deposits on PTFE Mitex membrane filters were analysed with ion chromatography (IC). The filters were first extracted in an ultrasonic bath with Milli-Q water and the extracts were analysed on Dionex anion chromatograph for sulphate $\left(\mathrm{SO}_{4}^{2-}\right)$ and on Dionex cation chromatograph for sodium $\left(\mathrm{Na}^{+}\right)$, potassium $\left(\mathrm{K}^{+}\right)$, magnesium $\left(\mathrm{Mg}^{2+}\right)$ and calcium $\left(\mathrm{Ca}^{2+}\right)$. The sample was driven through an anion exchange column together with a carbonate eluent for analysis of anions and through a cation exchange column together with a methylsulphonic acid eluent for analysis of cations. In the ion exchange columns, the ions are separated, conductivity of the eluent is reduced with a suppressor, and afterward the ions are detected with a conductivity detector.

The sampled PM deposits on PTFE Mitex membrane filters were analysed with Energy Dispersive $X$-ray Fluorescence (EDXRF) to obtain concentrations of the trace elements in the PM. EDXRF is a non-destructive method of analysing elements from $\mathrm{Si}$ to $\mathrm{U}$ in atomic weight. For experiments S1 the EDXRF analyses were performed at the Department of Chemistry, University of Gothenburg with a laboratory-built EDXRF; the samples from the S2 experiments were analysed at Cooper Environmental Services L.L.C., US as the University of Gothenburg instrument was not available at that time. Some samples from the S1 campaign were also analysed at Cooper Environmental Services L.L.C. to get intercomparison of results from the two laboratories. Agreement between the two laboratories was good. Analyses at the University of Gothenburg were made with a voltage of $50 \mathrm{kV}$ and a current of $25 \mathrm{~mA}$ applied to the silver $\mathrm{X}$-ray tube and spectra were collected for $1000 \mathrm{~s}$. The data from the EDXRF analyses were processed and quantified with the Quantitative X-ray Analysis System (QXAS) software developed by the International Atomic Energy Agency (IAEA), Vienna, Austria. For quantification of the detected elements, a calibration file was needed. The calibration file was created from single element standards during previous EDXRF sample analyses at the University of Gothenburg (Molnár et al., 2006). Detection limits were determined by analysis of blank membrane filters (Boman et al., 2009). They depend on the element under analysis and vary between $0.60 \mathrm{ng} \mathrm{cm}^{-2}$ and $90 \mathrm{ng} \mathrm{cm}^{-2}$ of filter area for the elements. Analyses performed at Cooper Environmental Services L.L.C., US were done on a Quanx EDX-771 energydispersive X-ray spectrometer with a 200 Watt rhodium target tube as an excitation source. The machine operation, data acquisition and spectral processing were handled by Kevex's software. Analyses followed EPA compendium IO 3.3 (US EPA, 1999).

For measurement of oxidative potential, samples taken on PTFE membrane filters as well as pieces of the quartz fibre filters were used. The samples were tested with the dithiothreitol (DTT) assay based on the method described by Cho et al. (2005). Earlier studies showed the correlation between DTT results and EC, OC and polycyclic aromatic hydrocarbons (PAHs) (Cho et al., 2005; Jeng, 2010; Li et al., 2003). First the filters were extracted with ethanol for 90 minutes in an ultrasonic bath. Next, the extracts were dried and redissolved in $100 \mu \mathrm{L}$ ethanol and $900 \mu \mathrm{L}$ Milli-Q water. The PM mass in the suspension obtained from PTFE filters was determined by weighing the filters before and after extraction in a conditioned weighing room. Quartz filters' extracts were filtered in order to remove quartz fibres which interfere with DTT measurement. As a result, quartz filters' extracts contain only the extractable fraction of collected PM. Regarding 
calculations of DTT results per PM mass, the total PM mass sampled on a quartz filter piece is used instead of the extractable mass since the later is not possible to determine. While the results are compared, measurements on PTFE filters are higher than DTT measured on quartz filters. This is due to the different extraction procedure and lower extraction efficiency for the quartz filters. The outcome is in line with results published by Yang et al. (2014). $100 \mu \mathrm{L}$ of the sample extract with known concentration of PM was incubated with $200 \mu \mathrm{L}$ of $0.5 \mathrm{mM}$ DTT in $0.1 \mathrm{M}$ potassium phosphate buffer ( $\mathrm{pH} 7.4)$ at $37^{\circ} \mathrm{C}$. The incubation times for the assay were $0,10,20,30,40$ and $50 \mathrm{~min}$. After the incubation time $300 \mu \mathrm{L}$ of $10 \%$ trichloroacetic acid was added. Next, $1 \mathrm{~mL}$ of $0.4 \mathrm{M}$ Tris-HCl, pH 8.9, with $20 \mathrm{mM}$ EDTA was mixed with $0.5 \mathrm{~mL}$ of the incubation mixture. Finally $30 \mu \mathrm{L}$ of $10 \mathrm{mM}$ beta dystrobrevin (DTNB) was added. Absorption of the formed 5-mercapto-2-nitrobenzoic acid was measured at $412 \mathrm{~nm}$ by spectrophotometry. The soot sample was used as a quality control. All results were corrected with DTT depletion rate of blanks, where instead of PM suspension Milli$\mathrm{Q}$ water was used. Three Milli-Q blanks were measured for each set of measurements. Coefficient of variance of Milli$\mathrm{Q}$ blank analyses was $1 \%$. The expanded uncertainty of the method is $35 \%$. In addition, 3 PTFE filter and 2 quartz filter field blanks were analysed. The average DTT depletion rate of the PTFE filter field blanks was $18 \%$ higher than the Milli-Q blanks, and the average DTT depletion of the quartz filter field blanks was $2 \%$ higher.

Microphysical and chemical analyses of PM samples were performed using several microscopic techniques. Special devices, each holding $4 \mathrm{Cu}$ microgrids with amorphous holey carbon film for electron microscopy and a Ge window for Fourier transform infrared spectroscopy (FTIR) were prepared. The transmission electron microscope (TEM) analyses of the samples collected on holey carbon film were done on TEM Philips CM20 FEG (CEMES, Toulouse) working at accelerating voltage $200 \mathrm{kV}$ in transmission bright field mode and in scanning transmission mode (Scanning Transmission Electron Microscopy, STEM). Other pictures were taken on the TEM JEOL JEM 3010 microscope (CINaM, Marseilles). Elemental composition was obtained by energydispersive X-ray spectroscopy (EDS) (Bruker AXS Microanalysis "Quantax") coupled to the TEM Philips CM20 FEG. Elemental analysis in STEM mode allowed us to create maps of the distribution of each element presented in the sample. In the TEM mode the elemental composition is obtained from the whole selected area.

The chemical nature of the particles was studied by FTIR. Spectra were measured at $4 \mathrm{~cm}^{-1}$ resolution using a Bruker Equinox 55 FTIR spectrometer (CINaM, Marseilles) equipped with a deuterated triglycine sulfate (DTGS) detector. For this analysis, Ge windows were exposed to the diluted exhaust in a similar way as filters for other PM analyses were. The spectra were also measured on a bulk soot powder collected on a metal sampling probe placed inside the exhaust duct during the entire PM sampling period. Prior to the analysis the powder was deposited directly on a bare $\mathrm{Ge}$ window without dilution into a solvent. Transmission spectra were recorded by averaging 400 scans in a typical wave number range from 4000 to $400 \mathrm{~cm}^{-1}$.

Raman spectra were taken on a XploRA Raman Microscope (Horiba Jobin Yvon, CEMES, Toulouse) with an excitation wavelength of $532 \mathrm{~nm}$. The objective of $\times 100$ and the grating of 1800 lines per $\mathrm{mm}$ were used. Spectra were taken at several areas of the sample and each spectrum was accumulated for $30 \mathrm{~s}$. The sample consisted of PM collected on a sampling probe stacked into the exhaust channel of the investigated main engine on $\mathrm{S} 1$, and covered both S1_HFO1\%_MEfull and S1_HFO1\%_MElow. The collected powder was placed on the glass slide without any solvent in order to prevent it from influencing the Raman spectra.

PM collected on quartz fibre filters was investigated by temperature-programmed oxidation (TPO). A diesel exhaust after-treatment model system (Messerer et al., 2006; Schmid et al., 2011) was used for oxidation of the soot samples in the temperature range of 100 to $700^{\circ} \mathrm{C}$. A total gas flow of $3.0 \mathrm{~L} \mathrm{~min}^{-1}$ of $95 \%$ nitrogen and $5 \%$ oxygen was streamed through the filter. The temperature of the gas was raised at a rate of $5 \mathrm{~K} \mathrm{~min}^{-1}$. Adjustment and control of the gas temperature were carried out using a type $\mathrm{K}$ thermocouple (HKMTSS-150, Newport Omega, Germany) placed in an immediate proximity of the filter surface. Combustion products $\mathrm{CO}$ and $\mathrm{CO}_{2}$ were analysed by FTIR spectroscopy (FTIR spectrometer IFS 66/s, Bruker, Germany) equipped with a $2 \mathrm{~L}$ gas flow cell with an optical path length of $6.4 \mathrm{~m}$. Before the experiments, the filters were pre-treated at $150^{\circ} \mathrm{C}$ under air for $30 \mathrm{~min}$ to remove residual water that would interfere with the FTIR analysis.

\section{Results and discussion}

\subsection{Emissions of gas-phase species and PM mass}

The emission factors for the measured gas-phase species and for PM mass obtained from gravimetry analyses of PTFE filters during the 6 experiments are shown in Table 2. The actual measured $\mathrm{NO}_{\mathrm{x}}$ emission factors are shown together with $\mathrm{EF}\left(\mathrm{NO}_{\mathrm{x}}\right)$ corrected for ambient conditions (humidity and temperature) as in the International Organization for Standarization (ISO) standard 8178-1 1996 clause 13.3 and with the maximum allowed $\mathrm{EF}\left(\mathrm{NO}_{\mathrm{x}}\right)$ for the engine calculated according to the TIER I $\mathrm{NO}_{\mathrm{x}}$ emission standard. A comparison of these two shows that the measured EFs were 16$35 \%$ lower on investigated MEs and $\sim 7 \%$ higher on the AE (S1_MGO_AE) than the TIER I standard maximum emission factors (Fig. S2 in the Supplement). Ship S1 is a preTIER ship while S2 is of TIER I standard. For S1 there is almost no difference between $\mathrm{EF}\left(\mathrm{NO}_{\mathrm{x}}\right)$ when the engine is 
at full load and when it is at low (30\%) load. In data from $\mathrm{S} 2$ one can see a decrease of $\mathrm{EF}\left(\mathrm{NO}_{\mathrm{x}}\right)$ when $\mathrm{HFO}$ fuel is changed to MGO, which is in agreement with a report of $\mathrm{EC}$ and Entec UK Limited (2002).

The EFs for $\mathrm{SO}_{2}$ are presented both as measured and as calculated from the fuel $\mathrm{S}$ content. For $\mathrm{S} 1$ experiments the measured $\mathrm{EF}\left(\mathrm{SO}_{2}\right)$ were $\sim 5 \%$ lower than the calculated ones, and the differences between measured and calculated $\mathrm{EF}\left(\mathrm{SO}_{2}\right)$ in the $\mathrm{S} 2$ experiments were $-20--30 \%$ ( $\sim 4 \mathrm{~g} \mathrm{~kg}^{-1}$ fuel for HFO in absolute numbers) for the $3 \mathrm{fu}-$ els tested. The observed sulphate in particulate phase corresponded to less than $1 \%$ of fuel $\mathrm{S}$ and could not be used to explain the discrepancy in the $\mathrm{S} 2$ experiment. This large discrepancy between the measured and calculated $\mathrm{EF}\left(\mathrm{SO}_{2}\right)$ persists also when ratios of $\mathrm{SO}_{2}$ and $\mathrm{CO}_{2}$ concentrations in the exhaust are compared to ratios of $\mathrm{S}$ and $\mathrm{C}$ content in the fuel (adjusted for molar weight differences), eliminating possible uncertainties in fuel consumption. Uncertainties of the fuel S analyses are 9, 11 and $20 \%$ for fuel S content of 1, 0.5 and $0.1 \%$, respectively, and the uncertainty of the fuel $\mathrm{C}$ analyses are is $3 \%$ (Table S3). Combination of these uncertainties gives maximum uncertainties for the $\mathrm{S} / \mathrm{C}$ ratio of \pm 12 , \pm 13 and $\pm 20 \%$ for fuels with FSC $1,0.5$ and $0.1 \%$, respectively. Uncertainties of the exhaust measurements are $\pm 2 \%$ for both $\mathrm{CO}_{2}$ and $\mathrm{SO}_{2}$, i.e. much smaller. Assuming all these uncertainties, we can conclude that the difference between the measured and calculated $\mathrm{EF}\left(\mathrm{SO}_{2}\right)$ is larger and systematically negative to be explained with the analytical uncertainties. Large differences between the measured and calculated $\mathrm{EF}\left(\mathrm{SO}_{2}\right)$ were found on the same ship during an earlier measurement campaign coordinated by the Joint Research Centre (JRC) (J. Hjorth, personal communication, 2008) and also in measurements on other ships. This issue has been a subject of scientific discussion for the past $2 \mathrm{yr}$. While the fuel separators remove mainly water and mineral particles, not largely affecting the $\mathrm{S}$ content, some $\mathrm{S}$ could be lost in the engine in reaction with lubricant $\mathrm{Ca}$ additive followed by removal of the solid reaction product $\left(\mathrm{CaSO}_{4}\right)$ to the lubricant sludge tank. A rough estimate of the lubricant needed to react with $10 \%$ of the fuel S based on measured lubricant Ca concentration, with an assumption of $100 \%$ reaction efficiency, gives the lubricant consumption needed $\sim 100 \mathrm{~kg} \mathrm{~h}^{-1}$, a factor of 40-300 higher than the lubricant consumption of 0.1$0.8 \mathrm{~kg} \mathrm{kWh}^{-1}$ given for a wide range of marine engines by engine producers (www.doosan.com). Hence, this study has not resulted in a satisfactory answer to the question of the missing S.

Emission factors for gaseous emissions measured under different engine loads are available for S1_HFO1 (Table 2) and also for S2_HFO1 and S2_MGO. EF( $\left(\mathrm{CO}_{2}\right)$ and $\mathrm{EF}\left(\mathrm{SO}_{2}\right)$ as $\mathrm{g} \mathrm{kg}^{-1}$ fuel did not show a dependence on engine load, which is in agreement with what was expected. Emission factors for the same gases in $\mathrm{g} \mathrm{kWh}^{-1}$ show a decrease from full to low load (80 to $30 \%$ ) on S1 due to the decreased specific fuel consumption (SFC). A decrease in engine load from 57

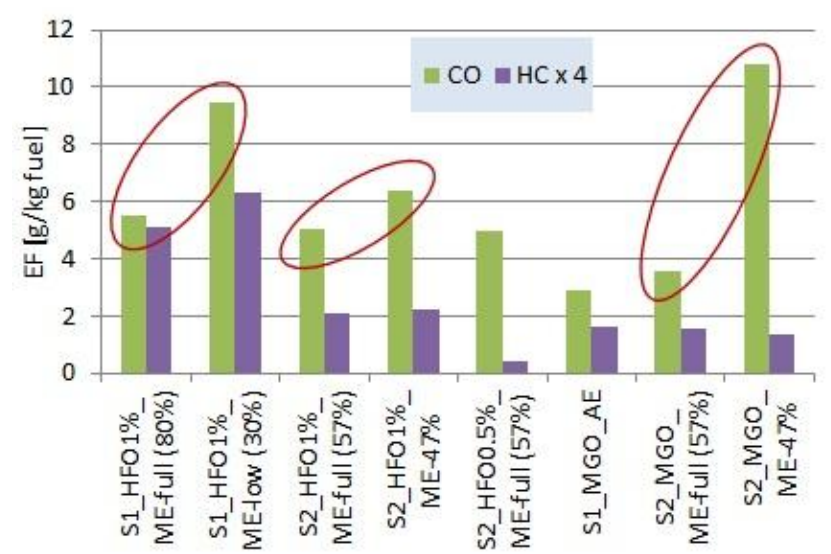

Fig. 1. $\mathrm{EF}(\mathrm{CO})$ (green) and $\mathrm{EF}(\mathrm{HC})$ (violet) at different engine loads. The red ellipses couple experiments performed on same engine and with the same fuel at different engine loads.

to $47 \%$ on $\mathrm{S} 2$ caused increases in $\mathrm{SFC}$ and $\mathrm{EFs}$ for $\mathrm{CO}_{2}$ and $\mathrm{SO}_{2}$ (expressed as $\mathrm{g} \mathrm{kWh}^{-1}$ ). The decrease was $1 \%$ and $4 \%$ for HFO with FSC $1 \%$ and MGO, respectively for all 3 parameters. Also, $\mathrm{EF}\left(\mathrm{NO}_{\mathrm{x}}\right)$ and $\mathrm{EF}(\mathrm{HC})$ (expressed as $\mathrm{g} \mathrm{kg}^{-1}$ fuel) did not differ significantly between the different engine loads, while CO showed increasing EFs with decreasing engine load (Fig. 1).

The emission factors for PM mass obtained for TSP, $\mathrm{PM}_{10}$ and $\mathrm{PM}_{2.5}$ or $\mathrm{PM}_{1}$ are presented in Fig. 2. All these EFs were somewhat larger for S1_HFO1\%_ME-full compared to S2_HFO1\%_ME-full. EFs for MGO fuel were similar for S1_MGO_AE and S2_MGO_ME-full. In S1 the EF(PM) decreased with decreased engine load. This is in agreement with earlier measurements performed by e.g. Fridell et al. (2008), Agrawal et al. (2010) and Petzold et al. (2010). Analyses of elemental composition of the sampled PM (Fig. 9 further in the text) confirmed that this decrease in $\mathrm{EF}(\mathrm{PM})$ is due to lower conversion of sulphur to sulphate in the exhaust at low engine load that exceeds the opposite trend in the $\mathrm{BC}$ and $\mathrm{EC}$ emissions with engine load. Comparing the different fuels, $\mathrm{EF}(\mathrm{PM})$ decreases from $\mathrm{HFO}$ with FSC $1 \%$, to HFO with FSC $0.5 \%$ to MGO with FSC $0.1 \%$. We could see an increase in PM mass, from $\mathrm{PM}_{2.5}$ or $\mathrm{PM}_{1}$ to $\mathrm{PM}_{10}$ and from $\mathrm{PM}_{10}$ to TSP, indicating the presence of coarse and giant particles. It should be noted that large particles can come from re-entrained soot and ash particles inside the exhaust channel. This was indicated by the online measurements which showed occasional presence of large particles not observed during the rest of the monitoring time period. Variability (coefficient of variance) of the $\operatorname{EF}\left(\mathrm{PM}_{\mathrm{x}}\right)$ obtained from PM mass on different filter samples taken during each individual experiment was between 4 and $18.9 \%$ on average. Uncertainty of the gravimetrical analysis as such for the investigated filters was less than $1 \%$ on average. 
Table 2. Emission factors for gas-phase species and mass of TSP, $\mathrm{PM}_{10}, \mathrm{PM}_{2.5}$ and $\mathrm{PM}_{1}$ measured during the experiments.

\begin{tabular}{|c|c|c|c|c|c|c|}
\hline Experiment & $\begin{array}{r}\mathrm{S} 1 \_ \text {HFO } 1 \% \text { _ } \\
\text { ME-full }\end{array}$ & $\begin{array}{r}\mathrm{S} 1 \_\mathrm{HFO}_{1 \%} \% \\
\mathrm{ME}-\mathrm{low}\end{array}$ & $\begin{array}{r}\mathrm{S} 2 \_\mathrm{HFO} 1 \%- \\
\text { ME-full }\end{array}$ & $\begin{array}{r}\mathrm{S} 2 \_ \text {HFO0.5\%_ } \\
\text { ME-full }\end{array}$ & $\begin{array}{r}\text { S1_MGO } \\
\text { AE }\end{array}$ & $\begin{array}{r}\text { S2_MGO_ } \\
\text { ME-full }\end{array}$ \\
\hline $\mathrm{EF}$ & {$\left[\mathrm{g} \mathrm{kWh}^{-1}\right]$} & {$\left[\mathrm{g} \mathrm{kWh}^{-1}\right]$} & {$\left[\mathrm{g} \mathrm{kWh}^{-1}\right]$} & {$\left[\mathrm{g} \mathrm{kWh}^{-1}\right]$} & {$\left[\mathrm{g} \mathrm{kWh}^{-1}\right]$} & {$\left[\mathrm{g} \mathrm{kWh}^{-1}\right]$} \\
\hline $\mathrm{CO}_{2}$ & 678 & 617 & 610 & 592 & 642 & 572 \\
\hline $\mathrm{O}_{2}$ & 1054 & 1127 & 841 & 786 & 1084 & 913 \\
\hline $\mathrm{CO}$ & 1.17 & 1.82 & 0.96 & 0.92 & 0.60 & 0.64 \\
\hline $\mathrm{HC}(\mathrm{C})$ & 0.27 & 0.30 & 0.10 & 0.07 & 0.32 & 0.07 \\
\hline $\mathrm{NO}_{\mathrm{x}}$ & 9.6 & 9.6 & 12.5 & 10.1 & 13.2 & 9.3 \\
\hline $\mathrm{NO}_{\mathrm{x}}$ corr. $^{\mathrm{a}}$ & 8.2 & 8.1 & 11.2 & 9.4 & 12.1 & 8.4 \\
\hline $\mathrm{NO}_{\mathrm{X}}$ TIER I $^{\mathrm{b}}$ & 12.0 & 12.0 & 12.9 & 12.9 & 11.3 & 12.9 \\
\hline $\mathrm{SO}_{2}$ & 3.65 & 3.24 & 2.8 & 1.5 & 0.12 & 0.27 \\
\hline $\mathrm{SO}_{2}$ calc. $^{\mathrm{c}}$ & 3.84 & 3.50 & 3.6 & 2.2 & 0.12 & 0.36 \\
\hline TSP & 0.58 & 0.34 & 0.37 & 0.23 & 0.07 & \\
\hline $\mathrm{PM}_{10}$ & 0.41 & 0.35 & 0.27 & 0.19 & 0.06 & 0.06 \\
\hline $\mathrm{PM}_{2.5}$ & - & - & 0.27 & 0.15 & - & 0.04 \\
\hline $\mathrm{PM}_{1}$ & 0.41 & 0.27 & - & - & 0.06 & - \\
\hline $\mathrm{EF}$ & {$\left[\mathrm{g} \mathrm{kg}^{-1}\right.$ fuel $]$} & {$\left[\mathrm{g} \mathrm{kg}^{-1}\right.$ fuel $]$} & {$\left[\mathrm{g} \mathrm{kg}^{-1}\right.$ fuel $]$} & {$\left[\mathrm{g} \mathrm{kg}^{-1}\right.$ fuel $]$} & {$\left[\mathrm{g} \mathrm{kg}^{-1}\right.$ fuel $]$} & {$\left[\mathrm{g} \mathrm{kg}^{-1}\right.$ fuel $]$} \\
\hline $\mathrm{CO}_{2}$ & 3204 & 3206 & 3219 & 3189 & 3151 & 3161 \\
\hline $\mathrm{O}_{2}$ & 4983 & 5862 & 4442 & 4235 & 5318 & 5043 \\
\hline $\mathrm{CO}$ & 5.52 & 9.46 & 5.06 & 4.98 & 2.92 & 3.55 \\
\hline $\mathrm{HC}(\mathrm{C})$ & 1.28 & 1.58 & 0.52 & 0.40 & 1.59 & 0.39 \\
\hline $\mathrm{NO}_{\mathrm{x}}$ & 45.2 & 49.7 & 66.1 & 54.2 & 64.6 & 51.6 \\
\hline $\mathrm{SO}_{2}$ & 17.3 & 16.8 & 14.9 & 8.2 & 0.57 & 1.51 \\
\hline TSP & 2.7 & 1.8 & 1.97 & 1.22 & 0.33 & - \\
\hline $\mathrm{PM}_{10}$ & 1.9 & 1.8 & 1.44 & 1.00 & 0.28 & 0.34 \\
\hline $\mathrm{PM}_{2.5}$ & - & - & 1.41 & 0.79 & - & 0.23 \\
\hline $\mathrm{PM}_{1}$ & 1.9 & 1.4 & - & - & 0.27 & - \\
\hline
\end{tabular}

${ }^{\mathrm{a}} \mathrm{NO}_{\mathrm{x}}$ corrected with factor for ambient conditions as in ISO 8178-1 1996 clause 13.3 version b. ${ }^{\mathrm{b}} \mathrm{NO}_{\mathrm{x}} \mathrm{EF}$ calculated according to the IMO TIER I standard, $\mathrm{EF}=45 \cdot n^{-0.2} \mathrm{~g} \mathrm{kWh}-1, n=$ engine speed in rpm. ${ }^{\mathrm{c}} \mathrm{SO}_{2}$ calculated from fuel sulphur content assuming complete oxidation to $\mathrm{SO}_{2}$.

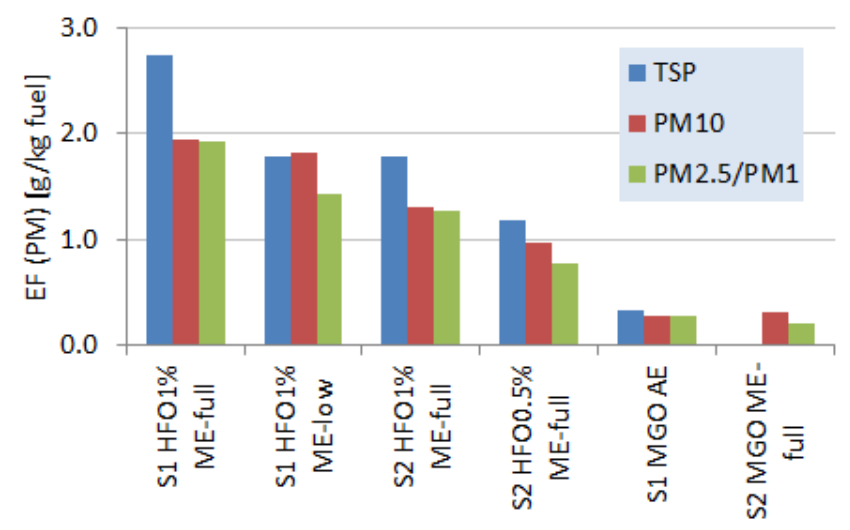

Fig. 2. EFs (in $\mathrm{g} \mathrm{kg}^{-1}$ fuel) for total suspended particulate matter (TSP), $\mathrm{PM}_{10}$ and $\mathrm{PM}_{2.5}$ obtained from gravimetric analyses of exposed PTFE filters.

\subsection{Emission factors for $\mathrm{PN}$ and particle size distributions}

Data from the EEPS and GRIMM 1108 instruments for particle number concentrations and size distributions are available for the S1 campaign only. The online PM measurements involve a set of instrumentation coupled either in series (FPS dilution system, DAD-100 secondary dilution, thermodenuder, EEPS) or in parallel (EEPS, GRIMM, tracer gas monitoring) (Figs. S1 and S2). Uncertainties of individual instruments, time resolution and time coordination of the data, as well as different dilution ratios of online instruments and filter sampling all contribute to the overall uncertainty and differences between data obtained from the different units. Physical principles of the particle sizing are different for EEPS (electrical mobility), GRIMM (optical) and PM cyclone (inertia), and soot-type particles with irregular shapes typically found in the exhaust will likely have a different diameter in each of the instruments. The consistency of the instruments could only roughly be checked by comparison of particle numbers measured by the GRIMM and EEPS instruments in the particle size range that is covered 


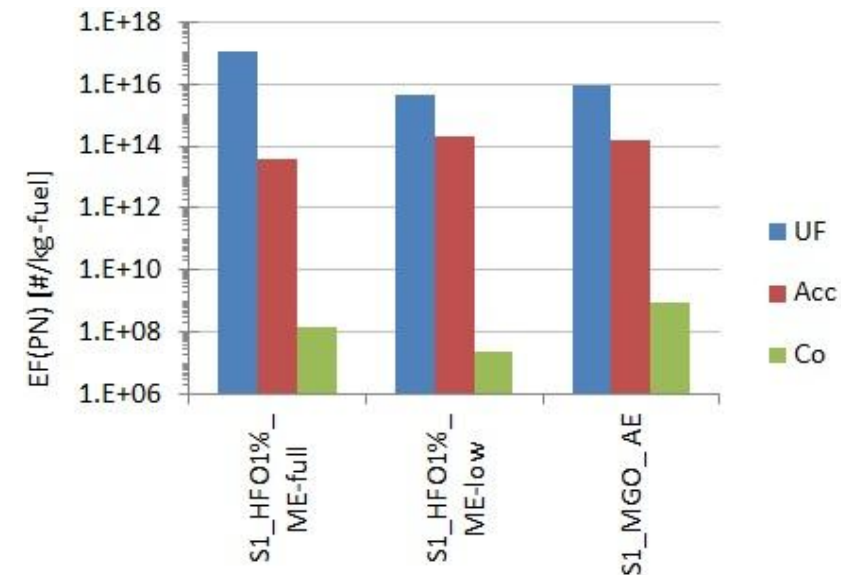

Fig. 3. Emission factors (in $\# \mathrm{~kg}^{-1}$ fuel) for particle numbers in 3 different size intervals. UF - ultrafine mode, $6 \mathrm{~nm}<\mathrm{Dp}<100 \mathrm{~nm}$, Acc - accumulation mode, $100 \mathrm{~nm}<\mathrm{Dp}<2.5 \mu \mathrm{m}$, Co - coarse mode, $2.5 \mu \mathrm{m}<\mathrm{Dp}<10 \mu \mathrm{m}$.

by both instruments, i.e. $300-500 \mathrm{~nm}$, (bearing in mind that EEPS gives electrical mobility diameter while GRIMM gives the optical diameter) and by comparison of PM mass calculated from size distributions (assuming PM specific mass of $1 \mathrm{~g} \mathrm{~cm}^{-3}$ ) with the filter gravimetry results. The first comparison is between two parallel instruments coupled to the same serial line for sampling. The size interval overlap of the online instruments $\sim 300-500 \mathrm{~nm}$ gave GRIMM/EEPS particle number concentration (PNC) mean values of $0.7-$ 3.8. The second comparison is between the parallel online instruments and measurements performed in different serial lines and shifted in time. Comparison of PM mass calculated from the online instrument data (assuming a unit particle density) agreed within a factor of 4 with data obtained from the filter gravimetry. The online data show a lower mass than gravimetry for the both HFO tests (S1_HFO1\%_MEfull, S1_HFO1\%_ME-low) and a higher mass than gravimetry for the MGO test (S1_MGO_AE). Considering the different physical principles of these two analyses, unknown specific density of the PM and uncertainty brought by the exhaust dilution and particle condensation issues, we consider this to be a consistent result. At the same time the difference demonstrates the uncertainties inherent in the PM measurements.

The EFs for particle numbers $\mathrm{EF}(\mathrm{PN})$ are presented in Fig. 3 as $\# \mathrm{~kg}^{-1}$ fuel. For S1_HFO1\%_full experiment, i.e. for the full engine load, the $\mathrm{EF}(\mathrm{PN})$ was $1.1 \times 10^{17} \# \mathrm{~kg}^{-1}$ fuel and for the S1_HFO1\%_low the EF(PN) was $4.9 \times$ $10^{15} \mathrm{~kg}^{-1}$ fuel. $\mathrm{EF}(\mathrm{PN})$ for the auxiliary engine burning MGO was $9.5 \times 10^{15} \# \mathrm{~kg}^{-1}$ fuel. The $\mathrm{EF}(\mathrm{PN})$ for S1_HFO1\%_full is ca. a factor of 2 higher than EFs found by Petzold et al. (2010) for full-load operation of ship engine using HFO, and a factor of 3-5 higher than the $\mathrm{EF}(\mathrm{PN})$ measured by Jonsson et al. (2011) in young plumes of 4
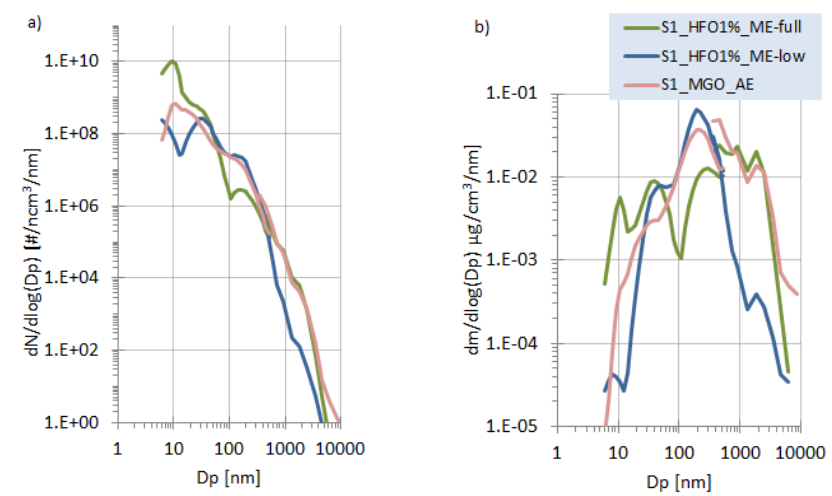

Fig. 4. Particle number and mass size distributions measured in the exhaust on S1 (recalculated for in-stack exhaust concentrations).

individual ships passing their on-shore measurement station in Göteborg (where maximum FSC of $1 \%$ is mandatory). Compared to mean $\mathrm{EF}(\mathrm{PN})$ from measurements in 72 plumes from ships with medium-speed diesel engines published by Lack et al. (2009) our $\mathrm{EF}(\mathrm{PN})$ is a factor of 10 higher; when the mean from all ships using fuel with FSC $>0.5 \%$ is considered, the difference is a factor of 5.5. The drop in $\mathrm{EF}(\mathrm{PN})$ with engine load is larger in our measurements (factor 22) than in Petzold et al. (2010) (factor 4-5). Figure 3 also shows the contribution of ultrafine (UF), accumulation mode (Acc), and coarse mode (Co) particles to the total particle number. One can see that the total is largely dominated by ultrafine particles. Comparing the number size distributions for the main engine at full and low engine loads, we can see much higher emission of particles with particle diameters $\sim 10 \mathrm{~nm}$ at full load compared to the low load. Taking the measured PM composition into consideration, we can speculate that higher amounts of sulphate formed at high engine load (Fig. 6) could result in nucleation of large number of volatile particles, while a lower sulphate formation at low engine load led to less nucleation and the condensable material in the exhaust could instead contribute to the growth of the ultrafine particles into the accumulation mode. The accumulation mode is higher in the low engine-load exhaust. This would mean that the increase in accumulation-mode particles is not a result of higher soot formation at low engine-load conditions, something that is actually supported by results of the EC analysis (Fig. 7). This can also be seen in number size distributions shown in Fig. 4. The measured particle number concentration is, however, sensitive to the dilution conditions. A brief test performed during the campaign has shown a sharp decrease of the number concentration with increasing primary dilution. Ristimaki et al. (2010) observed similar behaviour in PM mass concentration.

The PM mass is, by contrast, often dominated by particles in accumulation mode, as can be seen in the second panel of Fig. 4. In Fig. 4 a large difference between concentrations of particles with diameter above ca. $500 \mathrm{~nm}$ can be 

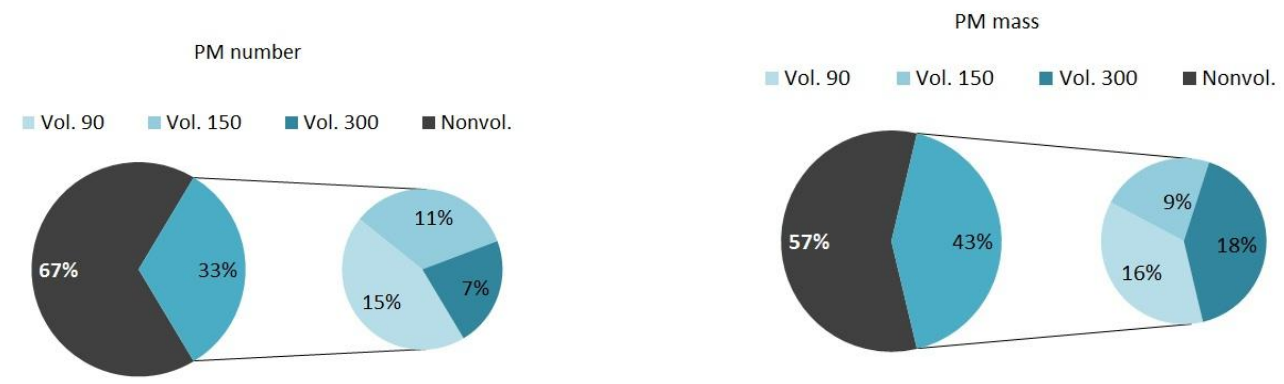

Fig. 5. Part of PM mass and PM number volatilised at $90^{\circ} \mathrm{C}$ (Vol. 90), $150^{\circ} \mathrm{C}$ (Vol. 150) and $300{ }^{\circ} \mathrm{C}$ (Vol. 300) in the thermodenuder, and the non-volatile part (Nonvol.).

seen. Figure S3 in the Supplement displays the same number size distributions together with \pm standard deviation intervals showing variance of the S1 measurement data. One can see that variability increases for large particles, and also that measurement under full-load conditions with higher flux and more turbulence in the exhaust channel displays more variability than measurement conducted under the low-load conditions. This indicates the importance of swirling and of the re-entrance of particles from the exhaust channel walls. Size distribution of particles emitted from the auxiliary engine shows few particles in the ultrafine mode and a peak at $\sim 200 \mathrm{~nm}$ similar to size distribution of S1_HFO1\%_MElow, while for particles with particle diameters $>300 \mathrm{~nm}$ the size distribution is more similar to that of S1_HFO1\%_MEfull. The exhaust flow in the channel was rather similar to that of the main engine at full load, which could, in combination with technical condition of the engine and exhaust system, explain presence of the coarse particles.

The volatility of particles was investigated with thermodenuder (TD) in experiment S1_HFO1\%_ME-full. We found that $33 \%$ of the particles (PN) and $42 \%$ of the PM mass were volatile. Figure 5 shows the fraction of PN and PM mass that was removed by the thermodenuder at 3 TD temperatures. The observed volatile $\mathrm{PN}$ fractions are on the low end of earlier published data. Petzold et al. (2010) found that $\sim 66 \%$ of the particles in their onboard measurements were volatile; Jonsson et al. (2011) found in measurements in passing plumes of 4 identified ships that $34-61 \%$ of particles were volatile; and Pirjola et al. (2011) found in similar inplume measurements that the volatile particles were responsible for $55-61 \%$ of the total particulate number. The differences could be the result of differences between the investigated engines and fuels as well as of differences in sampling conditions (dilution and temperature of sampled exhaust).

\subsection{PM composition}

The main components of the analysed PM are organic carbon (OC), elemental carbon (EC) and sulphate. The elements like $\mathrm{V}, \mathrm{Ni}, \mathrm{Ca}$ and $\mathrm{Zn}$ only make up a proportionally small part of the total PM mass. The mass closure of PM in our measurements has relatively large uncertainties, since EC and $\mathrm{OC}$ were measured on different filter samples (quartz) than sulphate and the other elements (PTFE) were. Figure 6 presents the composition of the sampled PM with respect to $\mathrm{EC}$, organic mass $(\mathrm{OM}=\mathrm{OC} \cdot 1.2$, Petzold et al., 2008), sulphate and associated water as well as other elements measured by ED XRF. Contributions of EC to the PM mass were between 10 and $35 \%$ and contributions of OM were between $25-60 \%$. The sum of volatiles (OM, sulphate and associated water) forms between 30 and $70 \%$ of the total PM (including the unidentified mass (UIM) equal to the difference between PM mass and sum of the measured individual species). For the S1_HFO1\%_ME-full measurement the compositionbased volatile part is ca. $50 \%$ (including UIM) or $75 \%$ (excluding UIM). This is more than the $42 \%$ observed with thermodenuder experiment. Assuming differences in these two methods, the lower dilution ratio used for filter sampling compared to that used for the online instruments and the fact that the ash elements are associated to mineral species like $\mathrm{CaSO}_{4}, \mathrm{CaO}, \mathrm{CaCO}_{3}, \mathrm{~V}_{2} \mathrm{O}_{3}$ and $\mathrm{Fe}_{2} \mathrm{O}_{3}$ (results of microchemical analyses later in the text, Moldanová et al., 2009; Popovicheva et al., 2012), taking up part of the assumed "volatiles", i.e. $\mathrm{C}$ and $\mathrm{SO}_{4}^{2-}$ and some additional mass in the form of unanalysed species, the difference is not very surprising.

In the following, the mean emission factors \pm standard deviation of the group of samples used as a measure of precision uncertainty are reported. The emission factors for EC and OC analysed by Sunset are presented in Fig. 7.

\subsubsection{Elemental and organic carbon}

The $\mathrm{EF}(\mathrm{OC})$ based on all samples taken from HFO exhaust was $0.59 \pm 0.15 \mathrm{~g} \mathrm{~kg}^{-1}$ fuel with somewhat higher $\mathrm{EF}(\mathrm{OC})$ for the HFO with $1 \%$ sulphur $\left(0.64 \pm 0.12 \mathrm{~g} \mathrm{~kg}^{-1}\right.$ fuel $)$ and lower for $0.5 \% \mathrm{~S}\left(0.43 \pm 0.13 \mathrm{~g} \mathrm{~kg}^{-1}\right.$ fuel). The two samples from the auxiliary engine running on MGO showed lower $\mathrm{EF}(\mathrm{OC}) 0.22 \pm 0.01 \mathrm{~g} \mathrm{~kg}^{-1}$ fuel. Emission factors for OC can be compared with $\mathrm{EF}(\mathrm{HC})$ expressed as $\mathrm{HC}-\mathrm{C}$ measured in the exhaust. For HFO experiments the $\mathrm{EF}(\mathrm{OC}) / \mathrm{EF}(\mathrm{HC}-\mathrm{C})$ was $58 \pm 21 \%$, for MGO the ratio was lower, ca. $14 \pm 0.5 \%$ 


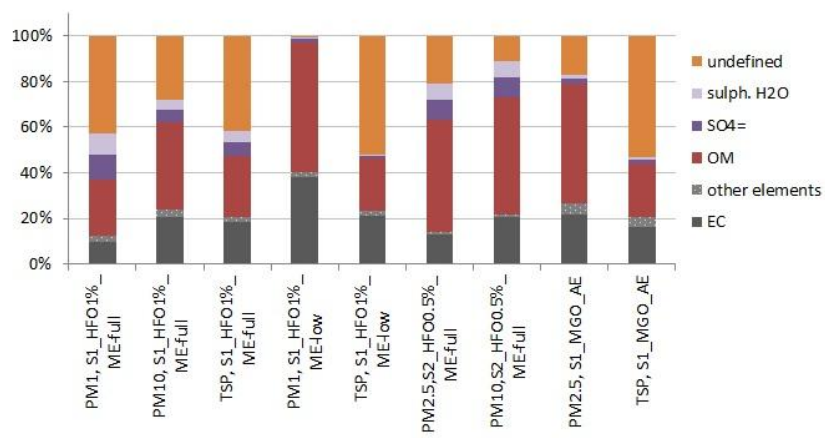

Fig. 6. Composition of $\mathrm{PM}$ sampled during $\mathrm{S} 1$ from the Sunset $(\mathrm{EC}, \mathrm{OM}=\mathrm{OC} \cdot 1.2)$ and $\mathrm{XRF}\left(\mathrm{SO}_{4}^{2-}\right.$, other elements) analyses. Sulphate-bound $\mathrm{H}_{2} \mathrm{O}$ is calculated as $\mathrm{SO}_{4}^{2-} \cdot 0.8$ (after Petzold et al., 2008).

(for $\mathrm{EF}(\mathrm{HC}-\mathrm{C})$ see Table 2). The $\mathrm{EF}(\mathrm{EC})$ for all samples in HFO exhaust was $0.34 \pm 0.15 \mathrm{~g} \mathrm{~kg}^{-1}$ fuel with higher $\mathrm{EF}(\mathrm{EC})$ for the HFO with $1 \%$ FSC $(0.40 \pm 0.12) \mathrm{g} \mathrm{kg}^{-1}$ fuel and lower for $0.5 \% \mathrm{FSC}\left(0.17 \pm 0.02 \mathrm{~g} \mathrm{~kg}^{-1}\right.$ fuel). The $2 \mathrm{MGO}$ samples showed $\mathrm{EF}(\mathrm{EC}) 0.14 \pm 0.04 \mathrm{~g} \mathrm{~kg}^{-1}$ fuel. The variability includes impact of different PM metrics and different engines investigated. An increasing $\mathrm{EF}(\mathrm{EC})$ and $\mathrm{EF}(\mathrm{PM}$ mass) can be seen from $\mathrm{PM}_{1}\left(\mathrm{PM}_{2.5}\right)$ over $\mathrm{PM}_{10}$ to TSP. This is, however, not true for $\mathrm{EF}(\mathrm{OC})$, where in some cases $\mathrm{EF}(\mathrm{OC})$ for $\mathrm{PM}_{10}$ were lower than those for $\mathrm{PM}_{2.5}$. This illustrates the uncertainties associated with the sampling of volatile PM. The coefficient of variation of $\mathrm{EF}(\mathrm{EC})$ and $\mathrm{EF}(\mathrm{OC})$ measured on multiple samples taken from the same experiment was 7.4 and $4.2 \%$, respectively.

\subsubsection{Black carbon}

The $\mathrm{EF}(\mathrm{EC})$ obtained from Sunset analyses were compared with corresponding $\mathrm{EF}(\mathrm{BC})$ calculated from Transmissometer analyses (using $\mathrm{MAC}=12.6 \mathrm{~m}^{2} \mathrm{~g}^{-1}$ ) and also with the few $\mathrm{EF}(\mathrm{BC})$ calculated from analyses with reflectometer. In Fig. 8 the EF for $\mathrm{EC}$ and for $\mathrm{BC}$ characterised by the two different analytical methods are compared. Figure 8 shows a very good agreement between the two different BC optical methods. Compared to these optical methods EC analysed with a thermal-optical method with transmission correction gives higher contribution to the total PM in all samples originating from HFO exhaust where $\mathrm{EF}(\mathrm{EC}) / \mathrm{EF}(\mathrm{BC})$ is $2.32 \pm 0.64$. Two $\mathrm{EC}$ samples taken in MGO exhaust show closer agreement with the $\mathrm{BC}$ analyses; $\mathrm{EF}(\mathrm{EC}) / \mathrm{EF}(\mathrm{BC})$ is $0.97 \pm 0.24$. Petzold et al. $(2010,2011)$ found higher $\mathrm{EF}(\mathrm{EC})$ compared to $\mathrm{EF}(\mathrm{BC})$ both for $\mathrm{HFO}$ and $\mathrm{MGO}$, their $\mathrm{EF}(\mathrm{EC}) / \mathrm{EF}(\mathrm{BC})$ ratios show strong positive correlation with engine load with values at $100 \%$ load $\sim 4$ for $\mathrm{HFO}$ and $\sim 9$ for MGO and at 10\% load 0.7-1.4 for HFO and 1.9 for MGO. In these studies BC was obtained from Multi-Angle Absorption Photometer MAAP (Thermo Scientific) $\left(\mathrm{MAC}=6.6 \mathrm{~m}^{2} \mathrm{~g}^{-1}\right.$ at $630 \mathrm{~nm}$ ) and $\mathrm{EC}$ from

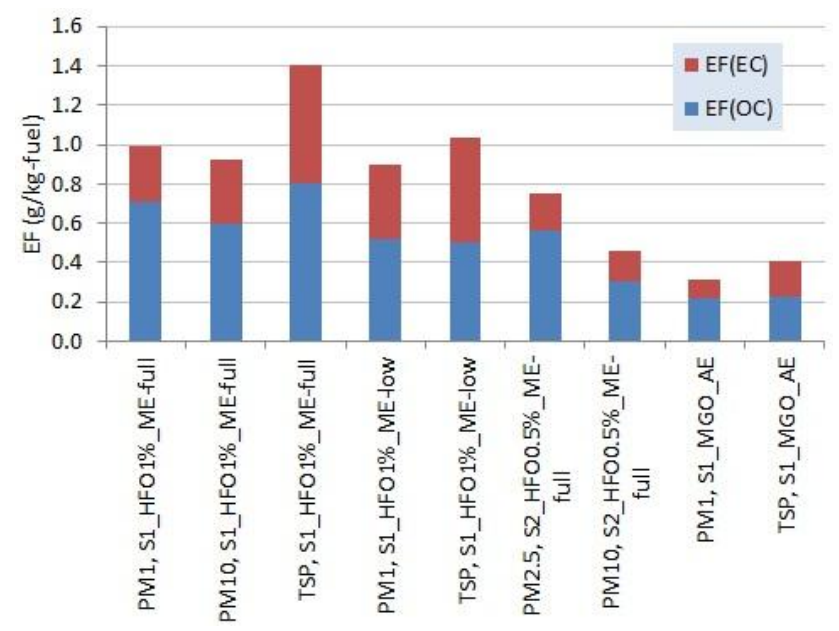

Fig. 7. Emission factors for elemental carbon (EC) and organic carbon (OC) analysed by Sunset on exposed quartz filters.

VDI-2 two-step thermographic method, i.e. the comparison is between two rather different quantities. However, the observed differences in the $\mathrm{EF}(\mathrm{EC}) / \mathrm{EF}(\mathrm{BC})$ ratios observed by Petzold et al. $(2010,2011)$ seem to be associated with combustion conditions (engine load) rather than the fuel type.

\subsubsection{Sulphur and metals}

Emissions of elements were calculated from masses obtained with XRF analyses of the PM sampled on PTFE filers. Emission factors for the most important species are presented in Fig. 9, and more detailed information is shown in Table S4 in the Supplement. As for some experiments two samples analysed at two different laboratories are available, these are both presented in the table to enable the comparison. It can be concluded that the results from the double samples are in a good agreement. Some filter samples were also analysed with ion chromatography performed on PM extracted from PTFE filters by Milli-Q water. These analyses gave results for EFs of PM-bound sulphate and calcium consistent with the EDXRF analyses. Table S4 also shows uncertainties of the EDXRF analysis for different types of samples as well as the coefficient of variance for the multiple samples analysed.

Emissions of S, V and $\mathrm{Ni}$ are mainly associated with fuel and comparison of the obtained emission factors in $\mathrm{g} \mathrm{kg}^{-1}$ fuel with the fuel content of these species is therefore interesting. Ratios of EF to fuel content $(\mathrm{EF}(x) /$ Fuel- $x, x$ is an element) for $\mathrm{S}, \mathrm{V}, \mathrm{Ni}$ and $\mathrm{Fe}$ are presented in Table 3. $\mathrm{EF}(x) /$ Fuel- $x$ for sulphur $0.1-0.8$ for samples in the HFO exhaust and 0.1-0.6 for samples in the MGO exhaust are on the low end of values of $1-5 \% \mathrm{~S}$ oxidised in exhaust that were found earlier (Moldanová et al., 2009; Petzold et al., 2010). Our results agree with the finding of Petzold et 


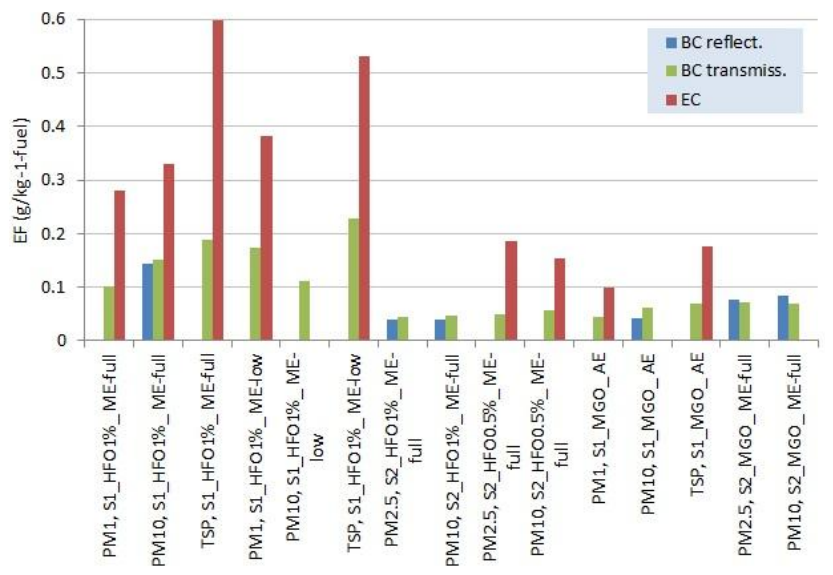

Fig. 8. Relative contributions of $\mathrm{EC}$ and $\mathrm{BC}$ to the $\mathrm{PM}$ mass on the analysed filters. BC was analysed with two different instruments, smoke stain reflectometer (reflect.) and SootScan transmissometer (transmiss.).

al. (2010), showing that oxidation of $S$ to sulphate and hence PM-bound $S$ increases with increasing engine load.

The S1_HFO1\%_ME-full experiment with high EFs for many elements had also significantly higher ratios of $\mathrm{EF}(x) /$ Fuel- $x, x$ being $\mathrm{V}, \mathrm{Ni}$ and $\mathrm{Fe}(60 \pm 1,90 \pm 8$ and $34 \pm 2 \%$ for $\mathrm{V}, \mathrm{Ni}$ and $\mathrm{Fe}$, respectively). This may be effect of the presence of ash particles entrained from the exhaust channel walls.

Analyses of lubricant oils in engines have shown high contents of $\mathrm{Ca}, \mathrm{P}$ and $\mathrm{Zn}$. Emissions of these species can be thus associated with the lubricant. From composition of fuel oil and lubricant, it was estimated that $\mathrm{Ca}$ in the sampled PM is predominantly of the lubricant origin, while for $\mathrm{Zn}$ contributions from fuel (HFO) and from the lubricant are of similar magnitude. The fuel and lubricant compositions are shown in Fig. 9 together with the emission factors for analysed elements, $\mathrm{S}$ shown as $\mathrm{S} / 100$ and lubricant concentrations in $100 \mathrm{mg} \mathrm{kg}^{-1}$. This scaling fits all elements and sources on one scale but also should be seen in context, with the found $\sim 1 \% \mathrm{~S}$ conversion to particulate sulphate and the ratio of fuel to lubricant consumption (which was of order of magnitude $n \cdot 100-2000$ ).

Among EFs for elements analysed with EDXRF, three different groups with high correlation $(r>0.85)$ were found. The first group includes $\mathrm{V}, \mathrm{Ni}, \mathrm{Fe}$ and $\mathrm{Si}$, which also have high correlation coefficients with EF for PM mass $(r \sim 0.9)$. The second group consist of $\mathrm{Cr}, \mathrm{Al}$ and $\mathrm{Mg}$, which have lower correlation with $\mathrm{EF}(\mathrm{PM}$ mass) $(r \sim 0.4-0.7)$, and third is made up of $\mathrm{Ca}$ and $\mathrm{Zn}$, which have the lowest correlation with $\mathrm{EF}(\mathrm{PM}$ mass $)(r \sim 0.4-0.7)$. Correlation of the particulate sulphur with any other element was not as high, likely due to the fact that it is, in contrast to metals, largely affected by engine operation conditions. The highest correlation of S was found with the elements in the first group, with $r$ 0.7-0.8.
Table 3. Ratios of emission factors in $\mathrm{g} \mathrm{kg}^{-1}$ fuel with the fuel content of these species.

\begin{tabular}{lrrrr}
\hline & $\mathrm{S}$ & $\mathrm{V}$ & $\mathrm{Ni}$ & $\mathrm{Fe}$ \\
\hline S1_HFO1 80 & $0.6 \pm 0.17 \%$ & $60 \pm 1 \%$ & $90 \pm 7 \%$ & $34 \pm 2 \%$ \\
S1_HFO1 30 & $0.1 \pm 0.00 \%$ & $29 \pm 6 \%$ & $51 \pm 11 \%$ & $19 \pm 7 \%$ \\
S2_HFO1 & $0.4 \pm 0.01 \%$ & $42 \pm 3 \%$ & $57 \pm 5 \%$ & $13 \pm 3 \%$ \\
S2_HFO0.5 & $0.4 \pm 0.05 \%$ & $40 \pm 2 \%$ & $67 \pm 3 \%$ & $11 \pm 2 \%$ \\
S1_MGO & $0.6 \pm 0.05 \%$ & $<$ d.1. & $<$ d.1. & $<$ d.1. \\
S2_MGO & $0.1 \pm 0.02 \%$ & $<$ d.1. & $<$ d.1. & $<$ d.1. \\
\hline
\end{tabular}

Table S5 in the Supplement presents sample Pearson correlation coefficients $r$ for the emission factors for different elements and PM mass.

\subsubsection{Oxidative potential}

The calculated DTT depletion rate normalised for the PM mass measured on PTFE filter samples was found to be between 0.01 and $0.04 \mathrm{nmolDTT} \mathrm{min}^{-1} \mu \mathrm{g}^{-1} \mathrm{PM}$ (Fig. 10a). The highest value was found for a PM sample in exhaust from MGO combustion in experiment S2, $0.038 \mathrm{nmol}$ DTT $\mathrm{min}^{-1} \mu \mathrm{g}^{-1}$ PM. PM from MGO exhaust in experiment $\mathrm{S} 1$ showed a mean value of $0.020 \mathrm{nmolDTT} \mathrm{min}^{-1} \mu \mathrm{g}^{-1} \mathrm{PM}$, close to the average of all analysed samples. It is therefore not possible to draw the conclusion that there is a systematic difference between oxidative potential of PM from MGO and HFO fuels based on our experiments. Oxidative potential measured on PM samples from HFO exhaust was between 0.01 and $0.02 \mathrm{nmolDTT} \min ^{-1} \mu \mathrm{g}^{-1} \mathrm{PM}$, with the lowest value measured on PM from $\mathrm{HFO}$ with $\mathrm{FSC} 0.5 \mathrm{wt} \%$. Biswas et al. (2009) and Cheung et al. (2009) found similar levels of DTT oxidation rate for emissions from road diesel vehicles - both fell into a range of 0.01$0.025 \mathrm{nmol}$ DTT $\min ^{-1} \mu \mathrm{g}^{-1} \mathrm{PM}$. Figure $10 \mathrm{~b}$ shows oxidation potential calculated as rate of DTT depletion per $\mathrm{kg}$ fuel consumed. With this metrics, oxidative potential of PM in exhaust from combustion of HFO with $1 \mathrm{wt} \%$ FSC was $30-40 \mu \mathrm{mol}$ DTT min ${ }^{-1} \mathrm{~kg}^{-1}$ fuel. Oxidative potential of PM in HFO with $0.5 \dot{\mathrm{w} t} \%$ FSC ex-

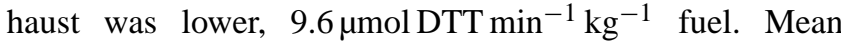
DTT depletion rate found for PM in MGO exhaust was $6.8 \mu$ mol DTT $\min ^{-1} \mathrm{~kg}^{-1}$ fuel.

The absolute values of oxidative potential found on quartz fibre filters were low due to the low extraction efficiency for $\mathrm{PM}$ on this material; however, these results were still suitable for studying correlation with OC and EC, especially as the EC/OC analyses were performed on the same filters. It is known that organic components can catalyse DTT oxidation (Li et al., 2003). On quartz filter samples high correlation between oxidative potential and OC (Pearson correlation coefficient $r=0.77$ ) and low correlation between oxidative potential and EC $(r=0.374)$ was found (Fig. S4 in the 

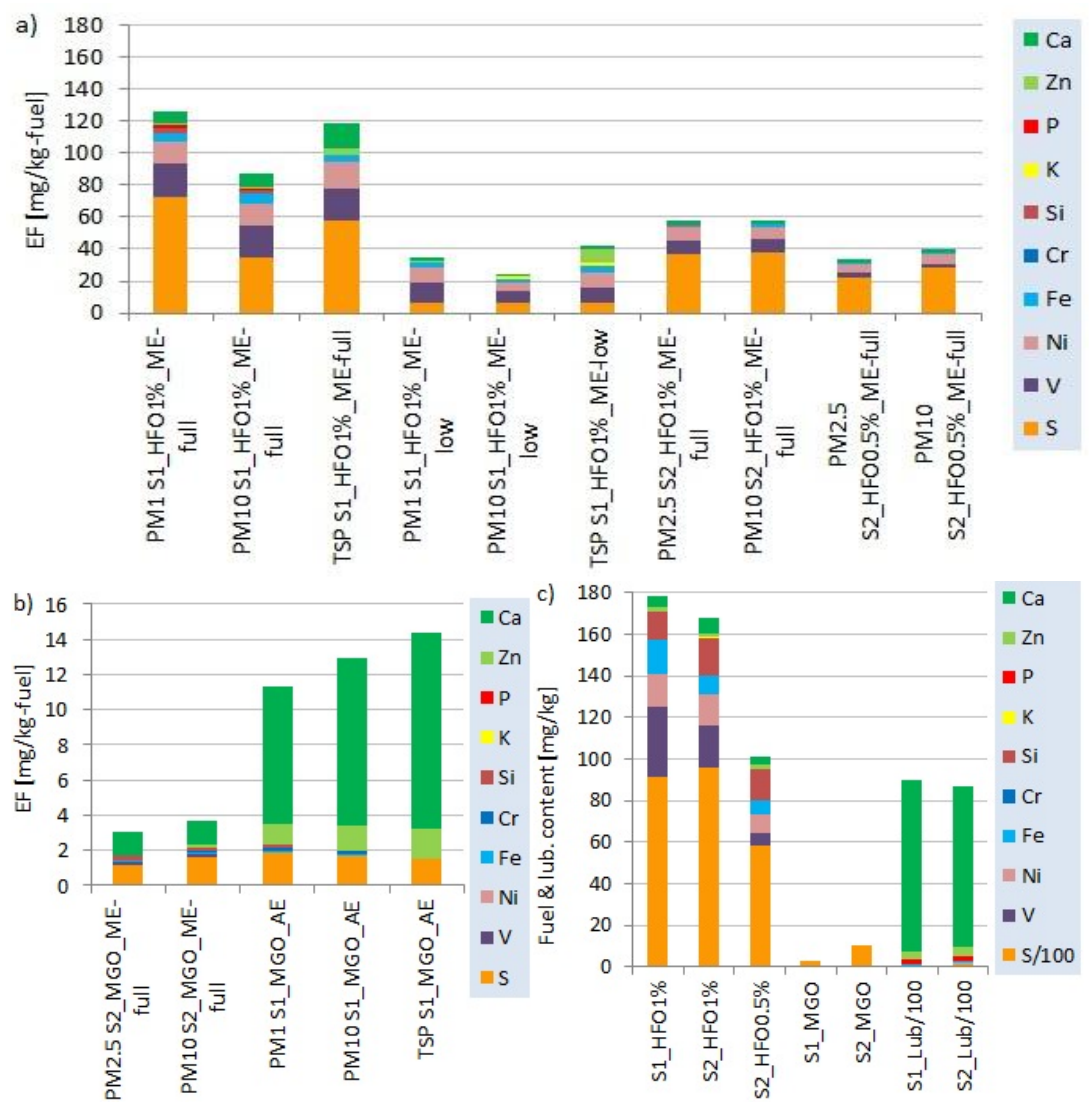

Fig. 9. Emission factors for elements based on XRF and IC analyses of PM filter samples. (a) Samples taken from HFO exhaust, (b) samples

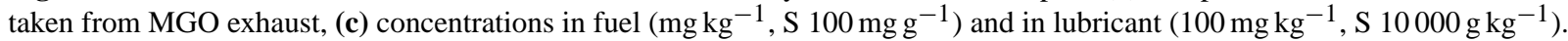

Supplement). Similar correlation levels between OC, EC and oxidative potential were found by Jeng (2010) and Biswas et al. (2009). In our study, a low negative correlation between oxidative potential measured on PTFE filters and $\mathrm{SO}_{4}^{2-}$ and metals was found. This is consistent with results presented by Biswas et al. (2009), Cheung et al. (2009) and Ntziachristos et al. (2007).

\subsubsection{Morphology, microstructure and chemical microcomposition}

Morphology, microstructure and chemical microcomposition of PM have been studied with samples taken from the diluted exhaust in experiments S1_HFO1\%_ME-full and S1_MGO_AE. Both samples have shown presence of small, almost spherical particles (soot-type particles) forming agglomerates, bigger spherical particles - char or char-mineral particles, big particles without any regular shape - mineral particles, and small $(\sim 10-30 \mathrm{~nm})$ amorphous organic particles. These particle types have already been observed in PM samples from ship exhaust by Popovicheva et al. (2009) and Moldanová et al. (2009). A TEM image of the PM sampled in the main engine exhaust is presented in Fig. 11.
Number size distributions of the primary soot particles (the simple spherical black carbonaceous particles) in soot agglomerates have been calculated for both experiments from ca. 500 images of primary soot particles representing 15-20 agglomerates. The experimental data were fitted with lognormal functions; the mean particle diameter was $37 \mathrm{~nm}$ with a standard deviation of 0.7 for S1_HFO1\%_ME-full and $30 \mathrm{~nm}$ with a standard deviation of 1.1 for S1_MGO-AE. The primary soot particle size distributions are presented in Fig. S5 in the Supplement. In the sample from HFO combustion in the main engine, different clusters of larger primary soot-type particles with $60-70 \mathrm{~nm}$ diameters were also observed. Presence of these larger primary soot particles is shown as zone 2 in Fig. 11b, while zone 1 in the same figure shows the more abundant primary soot particles with mean Dp $37 \mathrm{~nm}$.

The selected area electron diffraction (SAED) pattern of soot-type particles in both samples showed broad and diffuse rings (Fig. S6a in the Supplement) which correspond to randomly distributed crystallites of graphite also observed on soot samples by Murr and Soto (2005) and Chen et al. (2005). From this pattern inter-reticular distances $d h k l$ between crystallographic planes $(h, k, l)$ were calculated: for the S1_HFO1\%_ME-full sample $d_{002}=3.74 \pm 0.19 \AA, d_{10}$. 

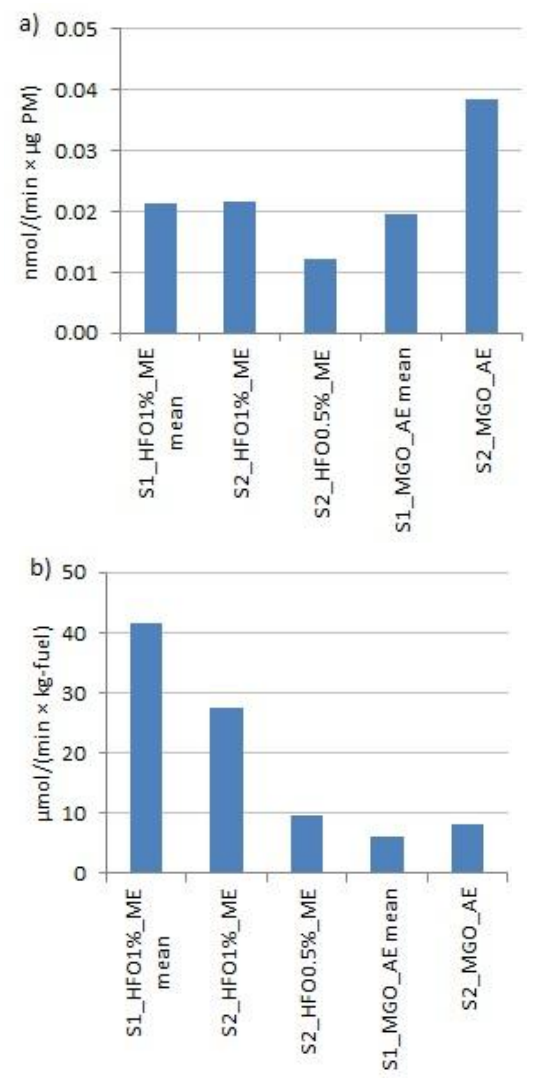

Fig. 10. Oxidative potential of investigated PM measured on PTFE membrane filter samples. (a) Specific for the emitted PM in nmol $\mathrm{DTT} /(\min \times \mu \mathrm{g}$ PM); (b) calculated for the emission source as nmol $\mathrm{DTT} /(\mathrm{min} \times \mathrm{kg}$ fuel $)$.

$1.98 \pm 0.10 \AA d_{11}=1.14 \pm 0.06 \AA$; for S1_MGO_AE sample $d_{002}=3.79=3.79 \pm 0.19 \AA, d_{10}=1.94 \pm 0.10 \AA, d_{11}=$ $1.13 \pm 0.06 \AA$. These values are typical for graphite microcrystallites with a turbostratic order (Vander Wal, 1997). In the S1_HFO1\%_ME-full sample, a different type of primary soot particles, with small dark points on the surface or inside the particles, was observed (Fig. S6b in the Supplement). The diffraction pattern of these polluted soot-type particles exhibits the diffused rings 10 and 11 with light dots on and between the rings. The ring 002 of graphite microcrystallites is not visible, indicating that the primary soot particles consist of randomly distributed graphene layers and do not possess any intergraphene layer long-range order (Chen et al., 2005). Thus, we should assume almost disordered carbon structure, already observed on soot-type particles sampled in heavy fuel oil exhaust (Popovicheva et al., 2009).

Figure 12 shows an example of a STEM image and of an elemental composition map of soot-type particles. More images are presented in the Supplement (Figs. S7-S11). Elemental composition of the primary soot particles from the S1-HFO1\%_ME-full experiment was found to be quite variable, some particles being composed of mainly $\mathrm{C}$ and
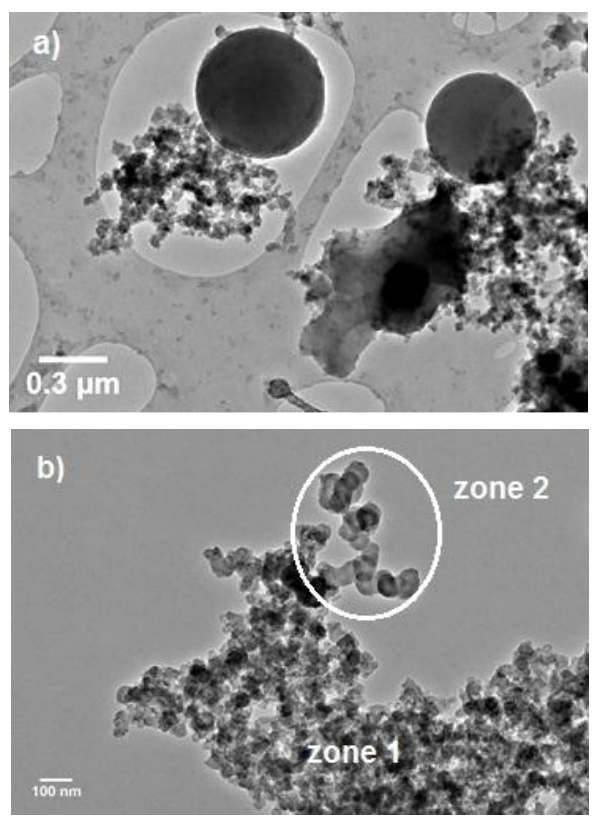

Fig. 11. TEM image of PM from the S1_HFO1\%_ME-full experiment. (a) Small magnification view showing soot-type, charmineral and mineral particles. (b) Primary soot-type particles of two different sizes, zone 1 - soot particles with $\mathrm{Dp} \sim 30-40 \mathrm{~nm}$, zone 2 - Dp 60-70 nm.

O (example in Fig. S7 with $92.6 \mathrm{wt} \% \mathrm{C}, 6.9 \mathrm{wt} \% \mathrm{O}$ and $<0.1 \mathrm{wt} \%$ traces of $\mathrm{Si}, \mathrm{S}, \mathrm{V}, \mathrm{Ni}$ and $\mathrm{Al}$ ), some showing high content of nitrogen (10-15\%) together with traces of $\mathrm{V}, \mathrm{Ca}$, $\mathrm{S}, \mathrm{Ni}$ and Si (e.g. Figs. 12, S8b and S9). The elemental composition maps show different areas where $\mathrm{N}, \mathrm{V}, \mathrm{S}$ and $\mathrm{Ca}$ are dominant, indicating different genesis of the individual primary soot particles. The soot-type particles collected in experiment S1_MGO_AE were mainly composed of C (77 wt \%), O (17 wt \%), Si (5 wt \%), and $\mathrm{Al}(1.5 \mathrm{wt} \%)$, with traces of S and Ca (Fig. S9).

The char and char-mineral particles come from incomplete combustion of fuel or lubricant droplets. The quantitative analysis of the EDS spectra of char-mineral and mineral particles showed carbon content of 50-70\%, oxygen content of $25-40 \%$ and traces of $\mathrm{S}, \mathrm{Ca}, \mathrm{Al}, \mathrm{Si}, \mathrm{V}, \mathrm{Ni}, \mathrm{Zn}$, and $\mathrm{P}$. Elements $\mathrm{Ca}, \mathrm{Zn}$ and $\mathrm{P}$ typically indicate that the particles have originated from lubricant, while $\mathrm{V}, \mathrm{Ni}$ and $\mathrm{S}$ are typical tracers of the HFO fuel. Many char-mineral particles collected in HFO exhaust show traces of elements from both groups (Fig. S8) which could either be result of internal mixing of elements in the exhaust into these particles or of the fact that both HFO and lubricants actually have some traces of all these species (Table S3). Assignment of fuel or lubricant origin to the char-mineral particles collected in MGO exhaust is easier, as $\mathrm{Ca}, \mathrm{Zn}$ and $\mathrm{P}$ in this case come only from the lubricant (Figs. S10 and S11). 

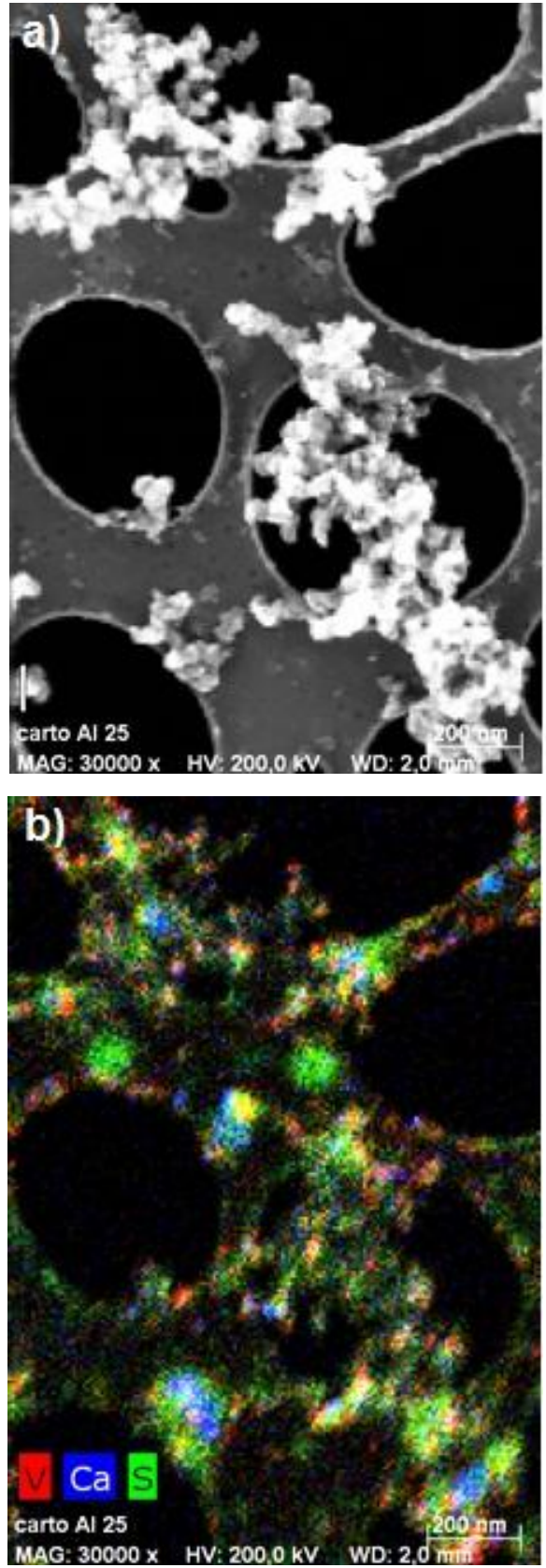

Fig. 12. (a) STEM image of an agglomerate of soot-type particles from the S1_HFO1\%_ME-full experiment. Composition: C $77.1 \mathrm{wt} \%, \mathrm{~N} 15.7 \mathrm{wt} \%$ and $\mathrm{O} 6.9 \mathrm{wt} \%$ and traces of $\mathrm{V}, \mathrm{Ca}$ and $\mathrm{S}$ (about $0.1 \mathrm{wt} \%$ of each element). (b) Elemental composition map of $\mathrm{V}, \mathrm{Ca}$ and $\mathrm{S}$ for the soot-type particles in (a).

The TEM images also have shown amorphous organic particles (no SAED pattern), smaller than soot particles with traces of $\mathrm{S}, \mathrm{V}, \mathrm{Ca}$ and $\mathrm{Al}$. On images of these particles one can see dark points, probably mineral impurities (Fig. S12). It is difficult to determine their exact elemental composition as they are located on the carbon amorphous film and are likely formed from carbon. The sulphur-rich areas outside soot clusters in Figs. 12 and S7b, often on the boarder of the carbon film, are probably these organic particles. One can notice that the particles interact with the high-energy electron beam of the microscope, which can be explained by the presence of semi-volatile compounds and absence of crystallised structure.

The elemental composition maps support the bulk EDXRF elemental analyses where weaker correlation between groups of elements $\mathrm{V}, \mathrm{Ni}$ and $\mathrm{Fe}$ on one side, $\mathrm{Ca}$ and $\mathrm{Zn}$ on the second side and $\mathrm{S}$ on the third were found, as both the primary soot particles and the char-mineral particles show variability in composition between these groups of elements.

The FTIR spectra measured on the S1_HFO1\%_ME-full and S1_MGO_AE samples were very similar and showed presence of aromatic compounds, $\mathrm{C}-\mathrm{O}$ and $\mathrm{C}=\mathrm{O}$ group, vanadium oxide $\mathrm{V}_{2} \mathrm{O}_{5}$, iron oxide, nitrogen-containing compounds, very strong peaks for sulphide compounds and another at $1108 \mathrm{~cm}^{-1}$ indicating sulfone, thiocarbonyl or C$\mathrm{O}-\mathrm{C}$ compounds (Fig. S13). These findings are supported by elemental composition obtained with EDS. The Raman spectra measured on cumulative PM sample collected on S1_HFO1\%_ME is presented in Fig. S14 in the Supplement. Five bands were identified, one $\mathrm{G}$ band corresponds to the graphite lattice and four D bands correspond to the disordered graphite structure and amorphous carbon. The ratio of the intensities in band $D_{1}$ to band $G$ is related to the average in-plane length $L a$ of a microcrystallite of graphite (Larouche and Stansfield, 2010; Ferrari and Robertson, 2000). For the investigated samples $L a=6.3 \mathrm{~nm}$, a value typical for carbon black particles (Larouche and Stansfield, 2010). The observed FTIR and Raman spectra are generally in agreement with results of Popovicheva et al. (2012) who measured these spectra on different samples from the same campaign. $\mathrm{N}$-species observed in this work were not detected by their system due to sensitivity limitations. Their analyses of Raman spectra showed, in addition to the signature of graphitic soot, also numerous inorganic compounds. These spectra were obtained on the ash residue after partial burn-out of the soot, a method not used in this work.

\subsubsection{The oxidation reactivity}

The oxidation reactivity of the main engine exhaust (S1_HFO1\%_MEfull) and the auxiliary engine exhaust (S1_MGO_AE50) were measured by TPO. The corresponding TPO profiles (plots of $\mathrm{CO}+\mathrm{CO}_{2}$ emissions against the sample temperature) for TSP and $\mathrm{PM}_{2.5}$ are shown in Fig. 13. The TPO profiles for various carbonaceous samples observed by Schmid et al. (2011) generally show an emission shoulder or minor peak at lower temperatures, followed by a main emission peak at higher temperatures. The shoulder or minor peak is assigned to amorphous or highly disordered soot structures, whereas the main emission peak is related to soot structures of higher structural order. The temperature of 

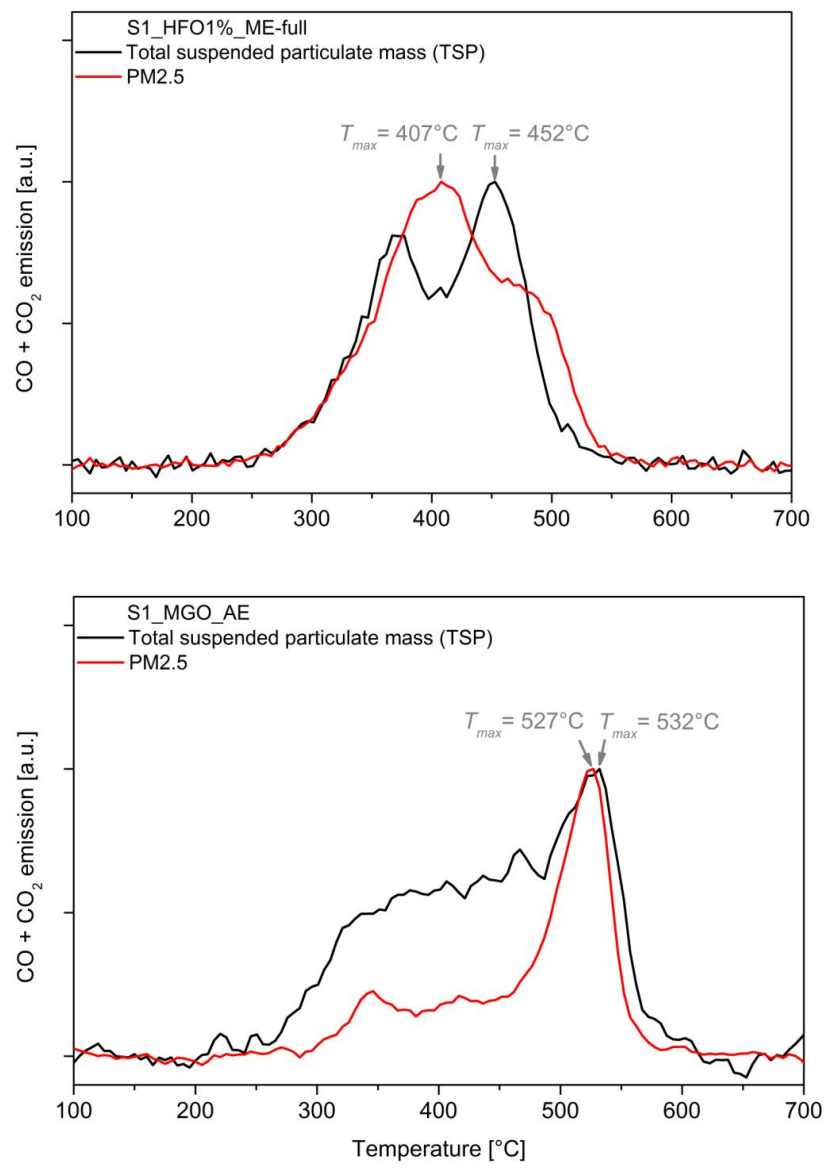

Fig. 13. Oxidation behaviour of PM (TSP in black and $\mathrm{PM}_{2.5}$ in red) sampled in (a) S1_HFO1\%_ME-full, (b) S1_MGO_AE experiments.

maximum $\mathrm{CO}$ and $\mathrm{CO}_{2}$ emission $\left(T_{\max }\right)$ of the main peak is defined as the reactivity parameter. The TPO profile of pure graphite demonstrated by Schmid et al. (2011) shows almost no emission up to $500^{\circ} \mathrm{C}$ and $T_{\max }$ of $760^{\circ} \mathrm{C}$. For spark discharge soot, Schmid et al. (2011) observed a pronounced emission shoulder due to amorphous and highly disordered domains and a comparatively broad main emission peak with $T_{\max }$ at $515^{\circ} \mathrm{C}$, representing the combustion of highly ordered soot structures. They also found that typical automotive diesel soot samples start to oxidize at $\sim 250^{\circ} \mathrm{C}$ and reveal maximum emission temperatures $T_{\max }$ between those of graphite and spark discharge soot, i.e. between 515 and $760^{\circ} \mathrm{C}$. Bladt et al. (2012) demonstrated that the iron oxide internally mixed with soot, especially at low concentrations (below $10 \mathrm{wt} \% \mathrm{Fe}$ ) shifts strongly $T_{\max }$ towards lower temperatures. Other contaminations, such as heavy metal oxides or salts, may also enhance soot reactivity (Neeft et al., 1997; Ciambelli et al., 1996; Castoldi et al., 2009). Thus, soot oxidation reactivity is influenced by both soot particle structure and the content of metal elements.
The TPO profile of PM from HFO exhaust, S1_HFO1\%_MEfull, consists of two emission peaks. Whereas the low temperature emission peak starts at $250^{\circ} \mathrm{C}$ and reaches its maximum at 366 and $407^{\circ} \mathrm{C}$ for the TSP and $\mathrm{PM}_{2.5}$ sample, respectively, the maximum of the high temperature peak is at 452 and $463{ }^{\circ} \mathrm{C}$, respectively. Both higher-temperature peaks in the two profiles have maxima at similar temperatures and probably present combustion of similar structural domains in soot, namely high-order soot structures also observed with SAED patterns with TEM (Fig. S6a). Compared to automotive diesel soot samples (Schmid et al., 2011), the temperatures of the emission maxima are very low. It is highly possible that the oxidation is catalysed by inorganic salts and/or oxides. Vanadium oxides and iron oxides are particularly known for their strong catalytic activity in soot oxidation (Bladt et al., 2012; Neeft et al., 1997) and these metals were found both by the EDXRF analyses of bulk PM (Fig. 9, Table S4) and with the microchemical analyses in STEM (Figs. 12 and S7-S11). Temperature at the maximum of the lower-temperature emission peak is lower for the TSP sample compared to the $\mathrm{PM}_{2.5}$ sample. Hence, these peaks belong to the combustion of different structural domains and/or are influenced differently by oxidation catalysts of different quantity or effectiveness.

The TPO profiles of S1_MGO_AE exhibit the main higher-temperature emission peak at 532 and $527^{\circ} \mathrm{C}$ in the TSP and $\mathrm{PM}_{2.5}$ samples, respectively, and broad emission shoulders starting at around 250 and $290^{\circ} \mathrm{C}$, respectively. Thus, there are soot components in S1_MGO_AE that start combusting at similar temperatures as in S1_HFO1\%_MEfull. Nevertheless, $T_{\max }$ of the S1_MGO_AE sample of TSP and $\mathrm{PM}_{2.5}$ are 80 and $64^{\circ} \mathrm{C}$, respectively - higher compared to the S1_HFO1\%_MEfull samples - and combustion is completed at temperatures about $50{ }^{\circ} \mathrm{C}$ higher. These findings can be explained by a lower reactivity of soot in S1_MGO_AE samples compared to the S1_HFO1\%_MEfull due to higher structural order of the soot and/or by lower content of oxidation catalysts. The structural order of the soot was analysed with the SAED patterns which, however, could not give any evidence of the difference in degree of crystallinity between the S1_HFO1\% and S1_MGO samples. Furthermore, the results of XRF analyses support the lower content of oxidation catalysts in the MGO sample as the concentrations of $\mathrm{V}, \mathrm{Ni}$ and $\mathrm{S}$ are low in the MGO exhaust sample relative to that from HFO. The relative intensity of the emission shoulders to their respective main peaks in S1_MGO_AE is lower for $\mathrm{PM}_{2.5}$ than for TSP and starts at a higher temperature. Accordingly, $\mathrm{PM}_{2.5}$ mostly contributes to the structural domains of higher order rather than to the structural domains of lower order in the TSP. 


\section{Conclusions}

The measurement campaigns investigated a number of parameters describing emission factors of gases and of particulate matter from ship engines. The measured EFs for PM mass were in the range of 0.3 to $2.7 \mathrm{~g} \mathrm{~kg}^{-1}$ fuel with lowest values for emissions from combustion of MGO and the highest for HFO. An increase of EF(PM mass) with increasing FSC and with engine load increasing from 30 to $80 \%$ was observed. For the dependence of EF(PM mass) on engine load, role of re-entrainment of soot and ash particles inside the exhaust channel walls at higher exhaust flow rates has been indicated by the online PM measurements.

The emission factors for particle numbers were measured for two different fuels and two engine operation modes. $\mathrm{EF}(\mathrm{PN})$ in the range $5 \times 10^{15}-1 \times 10^{17} \# \mathrm{~kg}^{-1}$ fuel were found, the number concentration is dominated by particles in the ultrafine mode and ca. $2 / 3$ of the particles are non-volatile. The data are consistent with those of earlier studies by Petzold et al. (2010) and Jonsson et al. (2011).

The PM mass is dominated by particles in accumulation mode and it consists of EC, OC and sulphate with associated water and various metal elements. The main metal elements in the case of $\mathrm{HFO}$ are $\mathrm{V}, \mathrm{Ni}, \mathrm{Fe}, \mathrm{Ca}$ and $\mathrm{Zn}$, and in the case of MGO are $\mathrm{Ca}, \mathrm{Zn}$ and $\mathrm{P}$. V and $\mathrm{Ni}$ are typical tracers of $\mathrm{HFO}$ while $\mathrm{Ca}, \mathrm{Zn}$ and $\mathrm{P}$ are tracers of the lubricant oil. EC makes up 10-38\% of the PM mass. The differences in $\mathrm{EC} / \mathrm{PM}$ mass ratios between $\mathrm{HFO}$ and MGO were found to be small. This finding is consistent with measurements published earlier, e.g. Petzold et al. (2010). EC and ash elements make up $23-40 \%$ of the PM mass, measurements with online instruments and thermodenuder indicated that ca. $60 \%$ of the mass is non-volatile. These two results have been found consistent when uncertainties associated with mass closure gap and differences in sampling techniques are assumed. In exhaust from HFO combustion, emission factors for BC measured with two different optical methods showed substantially lower values compared to those for $\mathrm{EF}(\mathrm{EC})$ obtained from thermo-optical method. The ratio $\mathrm{EF}(\mathrm{EC}) / \mathrm{EF}(\mathrm{BC})$ was $2.3 \pm 0.6$. For $\mathrm{MGO}$ exhaust $\mathrm{EF}(\mathrm{EC}) / \mathrm{EF}(\mathrm{BC})$ was $0.97 \pm$ 0.24 . Organic matter makes up $25-60 \%$ of the PM. The measured $\mathrm{EF}(\mathrm{OC})$ were $0.59 \pm 0.15 \mathrm{~g} \mathrm{~kg}^{-1}$ fuel for $\mathrm{HFO}$ and $0.22 \pm 0.01 \mathrm{~g} \mathrm{~kg}^{-1}$ fuel for MGO. The measured $\mathrm{EF}\left(\mathrm{SO}_{4}^{2-}\right)$ were low, ca. $100-200 \mathrm{mg} \mathrm{kg}^{-1}$ fuel for HFO with $1 \%$ FSC, $70-85 \mathrm{mg} \mathrm{kg}^{-1}$ fuel for HFO with $0.5 \%$ FSC and 3$6 \mathrm{mg} \mathrm{kg}^{-1}$ fuel for MGO. This corresponds to $0.2-0.7$ and $0.01-0.02 \%$ of fuel $\mathrm{S}$ converted to PM sulphate for HFO and MGO, respectively. For the low engine-load experiment, the $\mathrm{EF}\left(\mathrm{SO}_{4}^{2-}\right)$ was $18 \mathrm{mg} \mathrm{kg}^{-1}$ fuel, corresponding to $0.06 \%$ fuel $\mathrm{S}$ conversion.

The TEM and STEM images of collected PM have shown three different types of particles: (1) soot composed mainly of $\mathrm{C}, \mathrm{O}$, sometimes $\mathrm{N}$, and with traces of $\mathrm{Si}, \mathrm{S}, \mathrm{V}, \mathrm{Ca}$ and $\mathrm{Ni}$; (2) char and char-mineral particles composed of $\mathrm{C}, \mathrm{O}$, $\mathrm{Ca}$ and $\mathrm{S}$ (sometimes $\mathrm{Si}$ and $\mathrm{Al}$ ) with traces of $\mathrm{V}$ and $\mathrm{Ni}$ and sometimes P and (3) amorphous, probably organic particles containing sulphur and some vanadium. The maps of elements obtained from STEM showed heterogeneous composition of primary soot particles with respect to the trace metals and sulphur. SAED patterns of different soot particles show the presence of soot particles composed of microcrystallites with a turbostratic order and, in the HFO sample, also of particles of almost disordered carbon structure with light dots on and between the rings resulting from impurities. Composition of the char-mineral particles indicates that species like $\mathrm{CaSO}_{4}, \mathrm{CaO}$ and/or $\mathrm{CaCO}_{3}, \mathrm{SiO}_{2}$ and/or $\mathrm{Al}_{2} \mathrm{SiO}_{5}, \mathrm{~V}_{2} \mathrm{O}_{5}$ and iron oxide may be present; the last two were also confirmed by analyses of the FTIR spectra of the PM samples.

The temperature-programmed oxidation (TPO) of PM from the ship exhaust samples showed higher soot oxidation reactivity compared to automotive diesel soot; PM from the HFO exhaust is more reactive than PM from the MGO exhaust. This higher oxidation reactivity could be explained by high content of catalytically active contaminants, particularly in the HFO exhaust PM, for which the EDXRF analyses showed high content of $\mathrm{V}, \mathrm{Ni}$ and $\mathrm{S}$. Analyses of PM from the MGO exhaust identified only $\mathrm{Zn}, \mathrm{Ca}$, presumably less catalytically active species, and small amounts of S. It could be demonstrated that $\mathrm{PM}_{2.5}$ more strongly contributes to the main emission peak related to soot structures of higher structural order than to the minor emission peak related to highly disordered soot.

Oxidative potential measured as a rate of consumption of DTT was measured for the first time on PM from ship exhaust. The obtained values were between 0.01 and $0.04 \mathrm{nmol}$ DTT $\min ^{-1} \mu \mathrm{g}^{-1} \mathrm{PM}$, quite similar to the oxidative potentials of PM collected in urban and traffic sites.

The data obtained during the Transphorm experiments add information about emission factors for both gaseous and PMbound compounds from ship engines using different fuels and under different engine-load conditions. The observed variability of the EFs illustrates uncertainties of these emission factors as a result of measurement uncertainties, influences from trace components of fuels and lubricants and from differences between individual engines.

\section{Supplementary material related to this article is available online at http://www.atmos-meas-tech.net/6/ 3577/2013/amt-6-3577-2013-supplement.pdf.}


Acknowledgements. The financial support from EU FP7 project TRANSPHORM (no 243406), IVL foundation, StenaLine and Deutsche Forschungsgemeinschaft (DFG) are gratefully acknowledged. The authors would also like to thank Transatlantic, StenaLine and crew on both ships for their generous support of our measurement campaigns. Thanks to colleagues Kjell Peterson, Henrik Fallgren and Åsa Jonsson, all IVL, for assistance with the measurements, to Peter Molnar, Occupational and Environmental Medicine, University of Göteborg for assistence with the BC analyses on SootScan transmissometer and to Trine Underdal at DNV Petroleum services for assistance with the fuel and lubricant sample analyses.

Edited by: J. Hjorth

\section{References}

Agrawal, H., Welch, W. A., Miller, J. W., and Cocker III, D. R.: Emission measurements from a crude oil tanker at sea, Environ. Sci. Technol., 42, 7098-7103, 2008.

Agrawal, H., Welch, W. A., Henningsen, S., Miller, J. W., and Cocker III, D. R.: Emissions from main propulsion engine on container ship at sea, J. Geophys. Res., 115, D23205, doi:10.1029/2009JD013346, 2010.

Biswas, S., Verma, V., Schauer, J. J., Cassee, F. R., Cho, A. K., and Sioutas, C.: Oxidative potential of semi-volatile and non-volatile particulate matter (PM) from heavy-duty vehicles retrofitted with emission control technologies, Environ. Sci. Technol., 43, 39053912, 2009.

Bladt, H., Schmid, J., Kireeva, E. D., Popovicheva, O. B., Perseantseva, N. M., Timofeev, M. A., Heister, K., Uihlein, J., Ivleva, N. P., and Niessner, R.: Impact of Fe content in laboratory-produced soot aerosol on its composition, structure, and thermo-chemical properties, Aerosol Sci. Technol., 46, 1337-1348, 2012.

Boman, J., Gatari, M. J., Janhäll, S., Shannigrahi, A. S., and Wagner, A.: Elemental content of $\mathrm{PM}_{2.5}$ aerosol particles collected in Göteborg during the Göte-2005 campaign in February 2005, Atmos. Chem. Phys., 9, 2597-2606, doi:10.5194/acp-9-2597-2009, 2009.

Butterfield, D., Beccaceci, S., Sweeney, B., Green, D., Alexander, J., and Grieve, A.: 2009 Annual Report for the UK Black Carbon Network, NPL Report AS 52, ISSN 1754-2928, ikair.defra.gov.uk, 2010.

Castoldi, L., Matarrese, R., Lietti, L., and Forzatti, P.: Intrinsic reactivity of alkaline and alkaline-earth metal oxide catalysts for oxidation of soot, Appl. Catal. B, 90, 278-285, 2009.

Cavalli, F., Viana, M., Yttri, K. E., Genberg, J., and Putaud, J.-P.: Toward a standardised thermal-optical protocol for measuring atmospheric organic and elemental carbon: the EUSAAR protocol, J. Atmos. Meas. Tech., 3, 79-89, 2010,

http://www.atmos-meas-tech.net/3/79/2010/.

Chen, Y. Z., Shah, N., Braun, A., Huggins, F. E., and Huffman, G. P.: Electron microscopy investigation of carbonaceous particulate matter generated by combustion of fossil fuels, Energ. Fuel., 19, 1644-1651, 2005.

Cheung, K. L., Polidori, A., Ntziachristos, L., Tzamkiozis, T., Samaras, Z., Cassee, F. R., Gerlofs, M., and Sioutas, C.: Chemical characteristics and oxidative potential of particulate matter emissions from gasoline, diesel and biodiesel cars, Environ. Sci. Technol., 43, 6334-6340, 2009.

Cho, A. K., Sioutas, C., Miguel, A. H., Kumagai, Y., Schmitz, D. A., Singh, M., Eiguren-Fernandez, A., and Froines, J. R.: Redox activity of airborne particulate matter at different sites in the Los Angeles Basin, Environ. Res., 99, 40-47, 2005.

Chosson, F., Paoli, R., and Cuenot, B.: Ship plume dispersion rates in convective boundary layers for chemistry models, Atmos. Chem. Phys., 8, 4841-4853, doi:10.5194/acp-8-4841-2008, 2008.

Chow, J. C., Watson, J. G., Chen, L. W. A., Arnott, W. P., and Moosmuller, H.: Equivalence of elemental carbon by thermal/optical reflectance and transmittance with different temperature protocols, Environ. Sci. Technol., 38, 4414-4422, 2004.

Ciambelli, P., Corbo, P., Gambino, M., Palma, V., and Vaccaro, S.: Catalytic combustion of carbon particulate, Catal. Today, 27, 99106, 1996.

Cooper, D. A.: Exhaust emissions from high speed passenger ferries, Atmos. Environ., 35, 4189-4200, 2001.

Cooper, D. A.: Exhaust emissions from ships at berth, Atmos. Environ., 37, 3817-3830, 2003.

Corbett, J. J., Winebrake, J. J., Green, E. H., Kasibhatla, P., Eyring, V., and Lauer, A.: Mortality from ship emissions: a global assessment, Environ. Sci. Technol., 41, 8512-8518, 2007.

EC and Entec UK Limited: Quantification of Emissions from Ships Associated with Ship Movements between Ports in the European Community, European Commission, DG ENV.C1, Rue de la Loi, 200, 1049 Brussels, Belgium, 2002.

Endresen, Ø., Sørgård, E., Sundet, J. K., Dalsøren, S. B., Isaksen, I. S. A., Berglen, T. F., and Gravir, G.: Emission from international sea transportation and environmental impact, J. Geophys. Res., 108, D4560, doi:10.1029/2002JD002898, 2003.

Eyring, V., Köhler, H. W., van Aardenne, J., and Lauer, A.: Emissions from international shipping: 1. The last 50 years, J. Geophys. Res., 110, D17305, doi:10.1029/2004JD005619, 2005.

Eyring, V., Isaksen, I. S. A., Berntsen, T., Collins, W. J., Corbett, J. J., Endresen, Ö., Grainger, R. G., Moldanova, J., Schlager, H., and Stevenson, D. S.: Assessment of transport impacts on climate and ozone: Shipping, Atmos. Environ., 44, 3735-3771, 2010.

Ferrari, A. C. and Robertson, J.: Interpretation of Raman spectra of disordered and amorphous carbon, Phys. Rev. B, 61, 1409514107, 2000

Frank, N., Rice, J., and Tikvart, J.: Optical Measurements Of CSN and FRM Teflon Filters To Estimate Elemental Carbon To Support Health Studies, $\mathrm{PM}_{2.5}$ NAAQS Implementation And Climate, Abstract Air Pollution and Health conference, San Diego, CA, USA, March 2010, http://aaarabstracts. com/specialty/viewabstract.php?paper=429 (last assess: 22 October 2013), 2010.

Fridell, E., Steen, E., and Peterson, K.: Primary particles in ship emissions, Atmos. Environ., 42, 1160-1168, 2008.

Haeger-Eugensson, M., Moldanova, J., Ferm, M., Jerksjö, M., and Fridell, E.: On the increasing levels of $\mathrm{NO}_{2}$ in some cities - The role of primary emissions and shipping, IVL report B1886, available at: http://www.ivl.se/publikationer/importeradebrapporterrorej/ont heincreasinglevelsofno2insomecitiestheroleofprimaryemissions andshipping.5.7df4c4e812d2da6a416800035967.html (last access: December 2013), 2010. 
Hansen, A. D. A.: The Aethalometer. Usres manual, Magee Scientific, Berkeley, California, USA, www.mageesci.com (last access: December 2013), 2005.

Hong Kong EPD: 2010 Hong Kong Emission Inventory Report, Hong Kong Environmental Protection and Development report EPD/TR 1/12, available at: http://www.epd.gov.hk/epd/english/ environmentinhk/air/data/files/2010HKEIReportEng.pdf (last access: 4 December 2013), 2012.

IMO: MARPOL (Consolidated Edition), IMO, MEPC 58/23/Add.1, available at: http://www.imo.org/OurWork/Environment/ PollutionPrevention/AirPollution/Pages/Air-Pollution.aspx (last access: 17 April 2013), 2008

Jeng, H. A.: Chemical composition of ambient particulate matter and redox activity, Environ Monit. Assess., 169, 597-606, 2010.

Jonsson, Å. M., Westerlund, J., and Hallquist, M.: Size-resolved particle emission factors for individual ships, Geophys. Res. Lett., 38, L13809, doi:10.1029/2011GL047672, 2011.

Lack, D. A. and Corbett, J. J.: Black carbon from ships: a review of the effects of ship speed, fuel quality and exhaust gas scrubbing, Atmos. Chem. Phys., 12, 3985-4000, doi:10.5194/acp-12-39852012, 2012.

Lack, D. A., Corbett, J. J., Onasch, T., Lerner, B., Massoli, P., Quinn, P. K., Bates, T. S., Covert, D. S., Coffman, D., Sierau, B., Herndon, S., Allan, J., Baynard, T., Lovejoy, E., Ravishankara, A. R., and Williams, E.: Particulate emissions from commercial shipping: Chemical, physical, and optical properties, J. Geophys. Res., 114, D00F04, doi:10.1029/2008JD011300, 2009.

Larouche, N. and Stansfield, B. L.: Classifying nanostructured carbons using graphitic indices derived from Raman spectra, Carbon, 48, 620-629, 2010.

Lauer, A., Eyring, V., Hendricks, J., Jöckel, P., and Lohmann, U.: Global model simulations of the impact of ocean-going ships on aerosols, clouds, and the radiation budget, Atmos. Chem. Phys., 7, 5061-5079, doi:10.5194/acp-7-5061-2007, 2007.

Li, N., Sioutas, C., Cho, A., Schmitz, D., Misra, C., Sempf, J., Wang, M. Y., Oberley, T., Froines, J., and Nel, A.: Ultrafine particulate pollutants induce oxidative stress and mitochondrial damage, Environ. Health Persp., 111, 455-460, 2003.

Maenhaut, W.: Principles of thermal methods for the detection and differentiation of EC and OC, intercomparison results, in: Measurement of Elemental and Organic Carbon in Europe; Report of the preparatory workshop for a future standard measurement method, Kuhlbusch, T. A. J., et al., JRC EUR 23992 EN, 9-15, 2009.

Messerer, A., Niessner, R., and Pöschl, U.: Comprehensive kinetic characterization of the oxidation and gasification of model and real diesel soot by nitrogen oxides and oxygen under engine exhaust conditions: measurement, Langmuir-Hinshelwood, and Arrhenius parameters, Carbon, 44, 307-324, 2006.

Moldanová, J., Fridell, E., Popovicheva, O., Demirdjian, B., Tishkova, V., Faccinetto, A., and Focsa, C.: Characteri-sation of particulate matter and gaseous emissions from a large ship diesel engine, Atmos. Environ., 43, 2632-2641, 2009.

Molnár, P., Johannesson, S., Boman, J., Barregård, L., and Sällsten, G.: Personal exposures and indoor, residential outdoor, and urban background levels of fine particle trace elements in the general population, J. Environ. Monit., 8, 543-551, 2006.
Murr, L. E. and Soto, K. F.: A TEM study of soot, carbon nanotubes, and related fullerene nanopolyhedra in common fuel-gas combustion sources, Mater. Charact., 55, 50-65, 2005.

Neeft, J. P. A., Makkee, M., and Moulijn, J. A.: Catalysts for the oxidation of soot from diesel exhaust gases II. Contact between soot and catalyst under practical conditions, Appl. Catal. B-Environ., 12, 21-31, 1997.

NIOSH: Manual of Analytical Methods (NMAM). O'Connor PF, Schlecht, PC, Monitoring of diesel particulate exhaust in the workplace, Chapter Q, Third Supplement to NMAM, 4th Edn., NIOSH, Cincinnati, OH. DHHS (NIOSH) Publication No. 2003154, 2003.

Ntziachristos, L., Froines, J. R., Cho, A. K., and Sioutas, C.: Relationship between redox activity and chemical speciation of sizefractionated particulate matter, Particle and Fibre Tocicol., 4, 5, doi:10.1186/1743-8977-4-5, 2007.

Pettersson, J. B. C., Kovacevik, B., Wagner, A., Boman, J., and Laursen, J.: Elemental composition of fine particulate matter $\left(\mathrm{PM}_{2.5}\right)$ in Skopje, FYR of Macedonia, X-Ray Spectrometry, 40, 280-288, 2011.

Petzold, A., Hasselbach, J., Lauer, P., Baumann, R., Franke, K., Gurk, C., Schlager, H., and Weingartner, E.: Experimental studies on particle emissions from cruising ship, their characteristic properties, transformation and atmospheric lifetime in the marine boundary layer, Atmos. Chem. Phys., 8, 2387-2403, doi:10.5194/acp-8-2387-2008, 2008.

Petzold, A., Weingartner, E., Hasselbach, J., Lauer, P., Kurok, C., and Fleischer, F.: Physical properties, chemical composition, and cloud forming potential of particulate emissions from marine diesel engines at various load conditions, Environ. Sci. Technol., 44, 3800-3805, 2010.

Petzold, A., Lauer, P., Fritsche, U., Hasselbach, J., Lichtenstern, M., Schlager, H., and Fleischer, F.: Operation of Marine Diesel Engines on Biogenic Fuels: Modification of Emissions and Resulting Climate Effects, Environ. Sci. Technol., 45, 10394-10400, 2011.

Pirjola, L., Pajunoja, A., Malinen, A., Walden, J., Jalkanen, J.-P., Rönkkö, T., and Lähde, T.: Mobile measure-ments of ship emissions in two harbor areas in Finland, European Aerosol Conference, Abstract No. 973, 2011.

Popovicheva, O., Kireeva, E., Shonija, N., Zubareva, N., Persiantseva, N., Tishkova, V., Demirdjian, B., Moldanová, J., and Mogilnikov, V.: Ship particulate pollutants: Characterization in terms of environmental implication, J. Environ. Monit., 11, 2077-2086, 2009.

Popovicheva, O., Kireeva, E., Persiantseva, N., Timofeeva, M., Bladt, H., Ivleva, N., P., Niessner, R., and Moldanová, J.: Microscopic characterization of individual particles from multicomponent ship exhaust, J. Environ. Monit., 14, 3101-3110, 2012.

Quincey, P.: A relationship between Black Smoke Index and Black Carbon concentration, Atmos. Environ., 41, 7964-7968, 2007.

Ristimaki, J., Hellem, G., and Lappi, M.: Chemical and physical characterization of exhaust particulate matter from a marine medium speed diesel engine, CIMAC Congress, Bergen, Norway, 2010.

Schmid, J., Grob, B., Niessner, R., and Ivleva, N. P.: Multiwavelength raman microspectroscopy for rapid prediction of soot oxidation reactivity, Anal. Chem., 83, 1173-1179, 2011. 
Snijder, A. M., de Gier, C. W., and van den Elshout, J. H. H.: Modelling PM emission reduction scenarios in Rotterdam, DCMR Environmental Protection Agency, Rijnmond, Doc. no. 20770200, available at: www.dcmr.nl, 2008.

US EPA: Compendium Method IO-3.3:Retermination of metals in ambient particulate matter using $\mathrm{x}$-ray fluorescence (XRF) spectroscopy, Center for Environmental Research Information Office of Research and Development US Environmental Protection Agency, Cincinnati, OH 45268, 1999.

Vander Wal, R. L.: A TEM methodology for the study of soot particle structure, Combustion Sci. Technol., 126, 333-357, 1997. von Glasow, R., Lawrence, M. G., Sander, R., and Crutzen, P. J.: Modeling the chemical effects of ship exhaust in the cloudfree marine boundary layer, Atmos. Chem. Phys., 3, 233-250, doi:10.5194/acp-3-233-2003, 2003.

Yang, A., Jedynska, A., Hellack, B., Kooter, I., Hoek, G., Brunekreef, B., Kuhlbusch, T. A. J., Cassee, F. R., and Janssen, N. A. H.: Measurement of the oxidative potential of $\mathrm{PM}_{2.5}$ and its constituents: The effect of extraction solvent and filter type, Atmos. Environ., 83, 35-42, 2014. 